\title{
Examining the Impact of Surface Currents on Satellite Scatterometer and Altimeter Ocean Winds
}

\author{
Amanda M. Plagge And Douglas VAndemark \\ University of New Hampshire, Durham, New Hampshire \\ BERTRAND CHAPRON \\ IFREMER, Brest, France
}

(Manuscript received 24 January 2012, in final form 9 August 2012)

\begin{abstract}
A 5-yr dataset collected over two surface current and meteorological moorings allows rigorous evaluation of questions surrounding wave-current interaction and the scatterometer. Results demonstrate that scatterometer winds represent winds relative to the moving sea surface, affirming previous observational efforts that inferred the phenomenon using climatological approaches over larger time and space scales in equatorial and western boundary currents. Comparisons of wind residuals between Ku-band Quick Scatterometer (QuikSCAT) and buoy measurements show nearly one-to-one correlations with ocean surface velocity for $5-, 12.5-$, and $25-\mathrm{km}$ resolution wind speed products, especially under conditions of moderate wind speed and near-neutral atmospheric stability. Scatterometer and buoy wind direction differences due to currents were observed to be negligible for the range of surface velocities encountered and the length scales observed by QuikSCAT. Similar analyses are applied to C-band Advanced Scatterometer (ASCAT) satellite wind measurements at the same sites, as well as to satellite altimeter winds, and overall confirm the results seen with QuikSCAT; differences are likely the combined result of sampling, satellite wind algorithms, and geophysical wind-wave coupling in the presence of currents. On the whole, this study affirms that at length scales of $10 \mathrm{~km}$ and longer the scatterometer wind can be considered to be current relative. Observed differences between earth-relative and current-relative winds of order $10 \%-20 \%$ of the wind velocity are not uncommon in this and other ocean regions and this study more fully validates that microwave remote sensing winds appear to respond to wind stress even in the presence of larger-scale currents.
\end{abstract}

\section{Introduction}

The ever-increasing number of surface current measurements across the world's oceans is leading to renewed appreciation for the role that surface currents play in atmosphere-ocean dynamics. These observations, from drifters, gliders, profilers, and satellites within the global ocean observing system, present a next challenge: the incorporation of a fluid air-sea boundary condition into atmosphere-ocean coupling, with impacts both upon wind stress at the sea surface and the resulting ocean circulation (Kara et al. 2007), as well as atmospheric boundary layer modifications (Chelton et al. 2004; O’Neill

Corresponding author address: Amanda Plagge, Ocean Process Analysis Laboratory, University of New Hampshire, 8 College Rd., Durham, NH 03824.

E-mail: amanda.plagge@unh.edu et al. 2005; Chelton et al. 2006). As part of these issues, there is increased recognition of the fundamental effect of surface currents on near-surface wind speeds derived using satellite microwave systems. Winds inferred using these sensors rely on changes in surface backscatter or emission tied to the geometrical roughness changes driven by surface wind waves. In the presence of currents, waves will grow with the effective wind, leading many to directly interpret satellite winds as a wind stress or a current-relative wind, rather than one that is relative to the fixed-earth reference. While intuitive, supporting evidence for this premise remains limited (Dickinson et al. 2001; Quilfen et al. 2001; Chelton et al. 2004; Kelly et al. 2005) in large part because the effect is typically small with respect to the mean wind and because measurement approaches to quantitatively isolate the effect require an exacting approach. This study presents an attempt to more fully demonstrate surface current impacts 
within the context of satellite scatterometer ocean wind measurements.

Satellite scatterometry is the most widely applied approach for the global measurement of near-surface ocean wind speed and direction. The measurement principle involves radar detection of surface gravity and gravity-capillary wave changes that primarily reflect the winds observed near the air-sea interface (cf. Donelan and Pierson 1987). The complexity across multiple geophysical problems involved in analytically relating radar backscatter to waves and then to wind stress is daunting and, to date, the method for inverting wind vector data from radar observations is an empirical model function developed to relate in situ wind measurements to radar backscatter. This approach is mature (e.g., Stoffelen and Anderson 1997; Freilich and Dunbar 1999; Ebuchi et al. 2002; Tang et al. 2004; Hersbach et al. 2007; Bentamy et al. 2008; Hersbach 2010) and leads to global scatterometer wind products with accuracy of better than $1.2 \mathrm{~m} \mathrm{~s}^{-1}$ and $10^{\circ}$. However, scatterometry still has several issues to resolve or constrain if longterm, uniform, and climate-relevant wind vector data are to be produced. First, the satellite sensor community operates several different scatterometers with varying probing wavelengths ( $\mathrm{L}, \mathrm{C}$, and $\mathrm{Ku}$ bands) and viewing geometries; thus, a separate empirical model function is required in each case along with subsequent crossplatform consistency evaluations. Another issue is due to the fact that the scatterometer wind is derived from ocean wind waves and not the earth-relative wind itself. This point has led many to assume the scatterometer is a more closely akin to a wind stress measurement system (e.g., Weissman and Graber 1999). Yet, existing empirical scatterometer wind stress models or data products are limited, primarily because of the paucity of direct in situ wind stress observations, such as direct covariance flux estimates.

Using Monin-Obukhov similarity theory, the standard approximation relating the stress to the wind for the scatterometer is written in terms of a neutral atmospheric stability and current-relative wind vector at $10 \mathrm{~m}$ above the ocean (Liu and Tang 1996; Bourassa 2006):

$$
\mathbf{U}_{10 \mathrm{~N}}=\mathbf{U}_{s}+\frac{\mathbf{u}_{* a}}{\kappa} \ln z / z_{0}
$$

Here, the parameter $\kappa$ is von Kármán's constant, $\mathbf{u}_{* a}$ is the friction velocity, and the term $\ln z / z_{0}$ refers to the approximately logarithmic increase in wind speed with height. This term depends not only on altitude above the surface $(z$, here $10 \mathrm{~m})$ but on the properties of the surface (roughness length, $z_{0}$ ). The left-hand side of the equation can be derived in terms of measured scalars to yield a bulk $\mathbf{U}_{10 \mathrm{~N}}$; this is the usual means of developing a scatterometer wind vector geophysical model function (GMF). The term $\mathbf{U}_{s}$, the surface ocean current vector, is an additive term that assumes that currents dictate a fluid bottom boundary condition but do not impact, for example, the roughness length $z_{0}$.

Numerous past field and wave tank experiments (e.g., Plant 1977; Moore and Fung 1979; Donelan and Pierson 1987) have shown that radar backscatter is primarily induced by shorter gravity-capillary waves of order 1-20 cm. However, it is also known that different wave scales respond differently to changes due to atmosphere-ocean coupling attributed to all ocean and atmospheric boundary layer dynamics but are specifically reflective of atmospheric stability, frontal gradients in either fluid, longer gravity waves in the range from seas to swell, and wave-current interactions (Phillips 1977). Do all scatterometer model functions [the right-hand side of Eq. (1)] yield the same $\mathbf{U}_{10 \mathrm{~N}}$ and, more to the point, do $\mathrm{C}$ - and $\mathrm{Ku}$-band systems yield the same results for various geophysical conditions at the air-sea interface? In this paper we attempt to observationally address the following questions: Does the kinematic boundary condition hold for the pertinent wavelengths (i.e., do the applicable wind waves grow the same in and out of regions with a moving ocean)? Is this the same for Ku-band sensors as for $\mathrm{C}$ band? At what lengths and time scales is this true? The answers to these questions are crucial for several reasons. First, because synthetic aperture radar (SAR) wave-current studies have shown differences at $\mathrm{Ku}$ and C bands (Lyzenga 1998; Johannessen et al. 2005; Kudryavtsev et al. 2005; Marmorino et al. 2011). Next, because surface currents become more important as scatterometer applications are expanded and refined. These applications include but are not limited to 1) climate records, 2) finescale evaluations of air-sea coupling over frontal adjustment zones (eddies, the ITCZ, and western boundary currents), 3) assimilation of scatterometer winds into surface current products in regions with persistent strong currents such as the equatorial Pacific, and 4) any use of scatterometer winds in coastal regions with strong and highly dynamic currents.

The few observational studies addressing the effects of surface currents on scatterometer wind retrievals focus mostly in the equatorial region, where strong wavecurrent and air-sea interactions appear to complicate the relationship, and where only climatological or subsurface ocean current estimates have been used. For these reasons, many of the questions above remain. Kelly et al. (2005) show good agreement between zonal collocated wind differences and climatological zonal currents for Tropical Atmosphere Ocean (TAO) buoys and the Quick Scatterometer (QuikSCAT). Earlier, Quilfen et al. 
(2001) also showed a measurable but weak correlation between C-band scatterometer wind residuals and measured current at 10-m depth on two TAO buoys. However, both of these studies note that it is difficult to quantify the effect in part due to the lack of sufficient surface current measurements; additionally, the study of Kelly et al. (2005) was unable to find an expected relationship between meridional wind residuals and currents. As part of a comprehensive study of QuikSCAT wind vector accuracy at ocean buoys including TAO and various National Data Buoy Center (NDBC) buoys, Ebuchi et al. (2002) attempted to explain the differences between QuikSCAT and buoy winds by correlating the wind speed residuals with both sea surface temperature (SST) and the air-sea temperature difference. They suggested that the very low correlations that resulted might be due to neglecting the effects of surface currents, but their attempt to remove the current effects by repeating the study using only NDBC buoys outside the strong currents of the equatorial region produced correlations that were just as low.

Accordingly, our approach is to gain a larger sampling of data and range of surface and wind conditions by using a coastal region with a large diurnal reversing current and an extensive in situ near-surface current measurement record. We investigate the effects of surface currents on collocated scatterometer retrievals at both $\mathrm{Ku}$ and $\mathrm{C}$ bands, and with a data sample population large enough to permit filtering to ameliorate competing factors such as atmospheric stability and sea state. We include the assessment of current impacts on satellite altimeter winds (cf. Vandemark et al. 1997) for the same sites in order to infer if a broader portion of the ocean wave spectrum responds in a manner similar to that for the waves controlling the scatterometer signal.

\section{Data and methods}

The study site is the eastern Gulf of Maine centered about buoys $\mathrm{N}$ and $\mathrm{L}$, as noted in Fig. 1a, and the location was selected for several reasons. First, the region is known for strong reversing semidiurnal $\left(M_{2}\right)$ tides (Bigelow 1927; Dupont et al. 2003) that lead to a local daily variation in surface currents upward of -0.3 to $0.3 \mathrm{~m} \mathrm{~s}^{-1}$. The tides, combined with wind-driven and bathymetrically controlled coastal currents, provide a large dynamic range in the mean flow bottom boundary conditions for air-sea interaction and an average nearsurface current velocity of about $40 \mathrm{~cm} \mathrm{~s}^{-1}$ (Fig. 2) at both buoys $\mathrm{L}$ and $\mathrm{N}$. The second feature of the site is the long-term hourly record of both ocean currents and surface wind vector measured at these two buoys during a period of twice-daily satellite scatterometer passes that

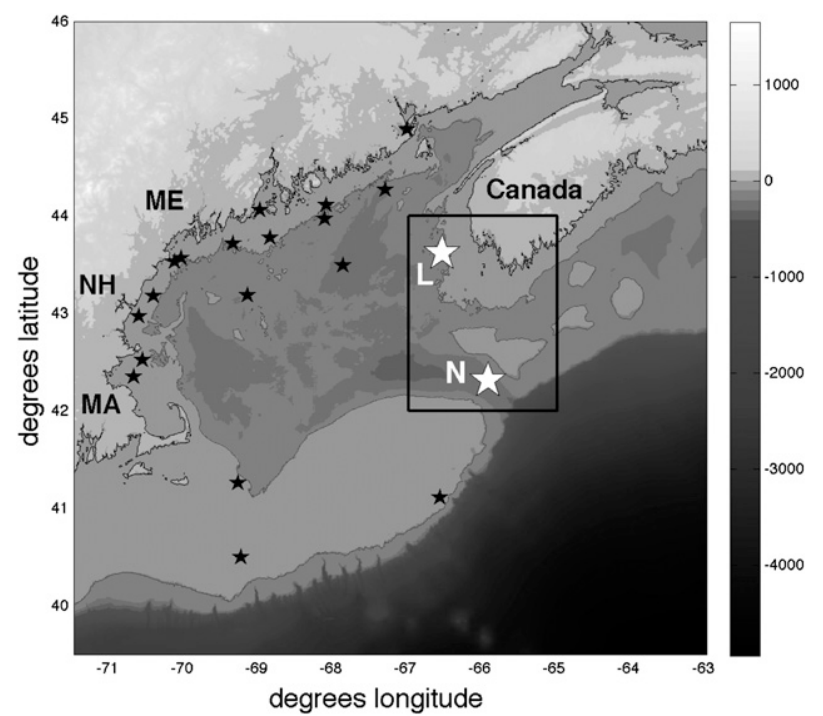

FIG. 1. Map of the Gulf of Maine region in the northeast United States and Canada including bathymetry and with the inset showing the study site. Star symbols indicate regional observing system buoys (black) with this study's surface current and wind measurement time series nodes, buoys $\mathrm{N}$ and $\mathrm{L}$, shown in white.

extends from 2004 to 2011 for buoy N and 2003 to 2008 for buoy L. Moreover, QuikSCAT wind vector measurements at multiple resolutions were recently validated in this region (Plagge et al. 2009) and thus the mean agreement between QuikSCAT and in situ winds for this site is well established. It should also be mentioned that buoys $\mathrm{L}$ and $\mathrm{N}$ are both in coastal waters, with distances from shore of 37 and $120 \mathrm{~km}$, respectively. While land contamination can, at times, bias scatterometer wind vector data (cf. Tang et al. 2004; Plagge et al. 2009), these impacts are typically seen for data within $14-80 \mathrm{~km}$ from shore. Despite buoy L being nearer to land than buoy N, Plagge et al. (2009) was able to affirm that for both buoy sites QuikSCAT data are not

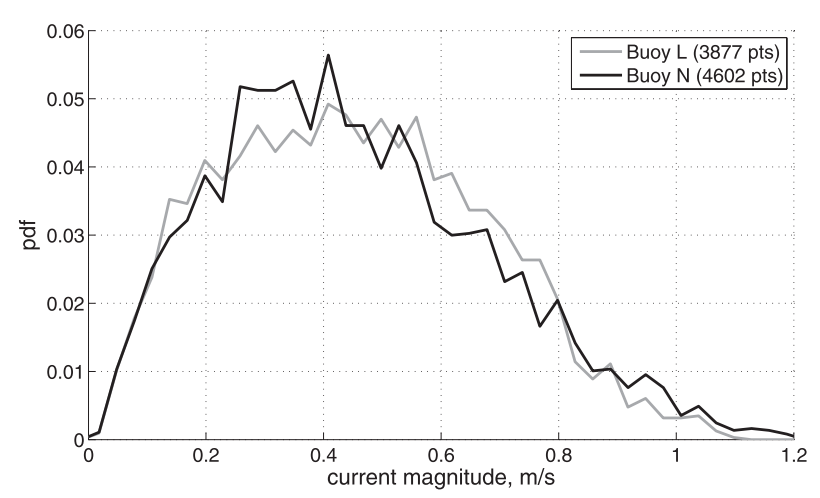

FIG. 2. Histogram of observed surface current magnitude for both buoys within the collocated datasets. 

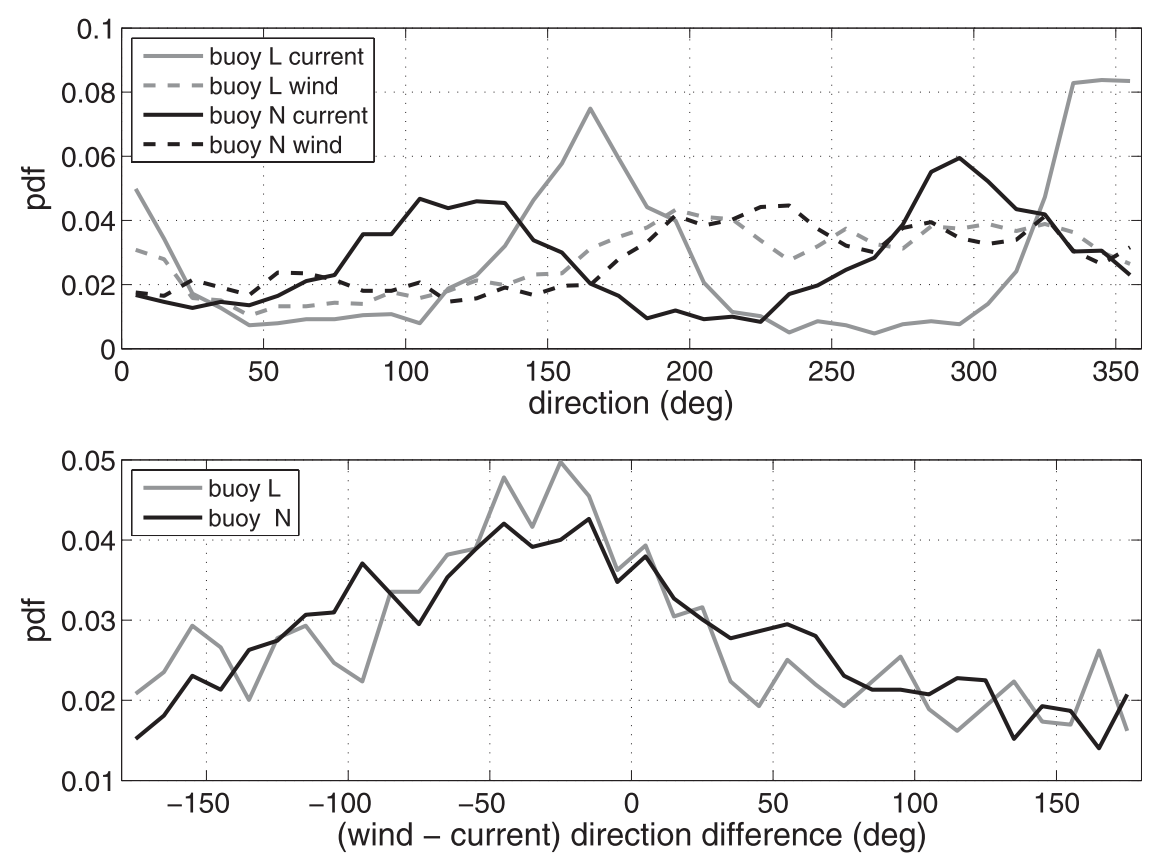

FIG. 3. (top) Histogram of observed wind and surface current directions for both buoys L and $\mathrm{N}$ and (bottom) the directional difference between the wind and the current. Both are provided using meteorological convention (direction from which the fluid arrives) and both are derived from the datasets used in Fig. 2.

contaminated by land effects. A final observation regarding the site concerns the spatial length scales associated with the surface currents at the two buoys. Buoy $\mathrm{N}$ is moored within the Northeast Channel, a region of deep water exchange for the Gulf of Maine, while buoy $\mathrm{L}$ is located north of Browns Bank and inflow from the coastal Scotian Current (Smith et al. 2001). In both cases, local bathymetry and the forcing lead to spatial variability in currents of $O(20-40 \mathrm{~km})$ (e.g., Manning et al. 2009). This issue will be addressed later in the study.

Buoy near-surface currents are measured using an Aanderraa model RCM 9 current meter with an accuracy of $0.15 \mathrm{~cm} \mathrm{~s}^{-1}$ or $1 \%$ of the reading and operated at 2-m depth, close enough to the surface to minimize the effects of shear with depth. Winds are measured using RM Young or Vaisala Windsonic anemometers with an accuracy of $0.3 \mathrm{~m} \mathrm{~s}^{-1}$ with 8-min-averaged winds every hour and obtained via the National Data Buoy Center (buoys N and L are NDBC stations 44024 and 44038 and are owned and operated by the University of Maine). Ancillary buoy measurements also utilized in this study are air and sea surface temperature, relative humidity, atmospheric pressure, and ocean significant wave height. To compare with scatterometer winds, the buoy wind measurements are adjusted to provide a 10-m neutral stability wind estimate using the Coupled Ocean-Atmosphere
Response Experiment (COARE) 3.0 bulk flux algorithm (Fairall et al. 2003). All wind data from this point forward are $10-\mathrm{m}$ neutral winds. Figure 3 provides the distribution of buoy-observed directions for the wind and surface current at both buoy locations within the total coregistered scatterometer-buoy database. The north-south (northwest-southeast) orientation of the $M_{2}$ tidal ellipse for buoy $\mathrm{L}(\mathrm{N})$ is apparent in the surface current record, as distinguished by the twin peaks in both solid lines in Fig. 3a. The directional difference between the wind and current vector is also shown and it is clear that a fairly uniform distribution between wind and current vectors is observed. As expected, this site yields a dataset with a wider range of wind current conditions than are found for equatorial regions with their more persistent winds and currents (Quilfen et al. 2001; Kelly et al. 2005).

The primary wind data for this study come from the QuikSCAT satellite Ku-band scatterometer and we evaluate data provided for three spatial resolutions: $25 \mathrm{~km}$ [level 2B (L2B) product from the National Aeronautics and Space Administration/Jet Propulsion Laboratory's (NASA/JPL) Physical Oceanography Distributed Active Archive Center (PODAAC)], 12.5 km (L2B, PODAAC), and 3-5 km (provided by D. Long of Brigham Young University). The latter are referred to as ultra-highresolution (UHR) data (Owen et al. 2003). Because 
regional surface current structures are of a finite spatial scale, it was desirable to examine all three data products to assess the potential impact of footprint size in this current impacts investigation. Although UHR data are still considered experimental, they have previously been validated in the Gulf of Maine (Plagge et al. 2009). To summarize the validation, UHR-buoy residuals are comparable with standard QuikSCAT products, with a slight increase in directional noise but additionally increased spatial enhancement of the frontal features. The selected wind vector cell (WVC) solution for each cell is the most likely choice as given by the direction interval retrieval with threshold nudging (commonly called DIRTH) algorithm, described in Dunbar et al. (2006).

The process for collocating in situ and QuikSCAT data both spatially and temporally is documented in previous work (Plagge et al. 2009). Briefly, collocated wind observations between the buoy and scatterometer must occur within 30 min (buoy-based current and wind measurements are effectively coincident). For every pass within the time frame of a given buoy-scatterometer match, all scatterometer wind vector cells within a 10-km radius of the buoy have been averaged to provide the average wind speed and direction for each resolution. This process provides a total of 4739 triplet matches (scatterometer, buoy wind, and current data) for the UHR, 3996 matches for the $12.5-\mathrm{km}$ dataset, and 2250 matches for the $25-\mathrm{km}$ product. It should be noted that during previous investigations (i.e., Plagge et al. 2009), this type of collocation (using the average within a given radius) was compared with the "nearest neighbor" collocation in this region and with these buoys, with no significant difference between the resultant scatterometer-buoy residuals. Additionally, although each product has a different number of triplet collocations, using only points where all three product triplets are available produces results that are statistically invariant compared to using all available data. Therefore, the dataset retains all possible triplets, meaning there are instances where, for instance, only the UHR product has a collocation.

As discussed in Ebuchi et al. (2002), it is important to consider and address data quality flagging and scatterometer wind vector ambiguity selection in any detailed analysis of wind residuals. Several prefiltering steps are taken prior to analyses. For all scatterometer products, and before collocation, any wind vector cell estimate flagged as occurring during rain is rejected. Next, any triplet where any wind speed lies above $18 \mathrm{~m} \mathrm{~s}^{-1}$ or where the current magnitude lies outside of three standard deviations of the overall mean current for the dataset is rejected to exclude infrequent extreme event data. Finally, cases where the scatterometer direction estimate lies beyond $45^{\circ}$ from the buoy are rejected as being cases of poor WVC ambiguity selection. After these latter quality control steps, there are 3627,3250 , and 1862 triplets remaining for the UHR and $12.5-$ and $25-\mathrm{km}$ sources, repectively. Overall, the results of following analyses with and without such filtering are statistically similar excepting slightly improved linear correlation coefficients.

Comparisons of QuikSCAT and buoy wind speeds from the resulting dataset are shown in Fig. 4 for each resolution and buoy, with the linear correlation coefficient and a linear least squares regression fit between the data shown in each panel. The level of agreement between satellite and in situ data is consistent with that obtained in the previously cited studies in terms of standard deviation and bias, although one does observe a systematic scatterometer wind overestimation above $12-15 \mathrm{~m} \mathrm{~s}^{-1}$ in all three products and at both buoys, an observation also noted in previous work in the Gulf of Maine (Plagge et al. 2009).

Our approach to a broader assessment of current impacts on satellite microwave sensor winds at this site entails performing similar matchup comparisons and analyses of C-band scatterometer and $\mathrm{Ku}$-band satellite altimeter data, following on from earlier studies that worked with much smaller datasets (Quilfen et al. 2001; Vandemark et al. 1997). The first additional matchup datasets contain measurements from the Advanced Scatterometer (ASCAT) sensor, operated by the European Organisation for the Exploitation of Meteorological Satellites (EUMETSAT) as part of the $M e t O p$ - $A$ platform. ASCAT operates at a C-band frequency, and standard data products have been provided at $25-$ and $12.5-\mathrm{km}$ resolutions since 1 November 2007 (EUMETSAT 2011). Bentamy et al. (2008) indicates that ASCAT winds are comparable to QuikSCAT winds globally, and have similar root-mean-squared differences when compared with buoy data $\left(1.72 \mathrm{~m} \mathrm{~s}^{-1}\right.$ and $\left.18^{\circ}\right)$. Since September 2010, a newer type of ASCAT wind vector retrieval, cited as the coastal product, also provides $12.5-\mathrm{km}$ resolution data but utilizes a different processing method than the standard ASCAT products (Verhoef and Stoffelen 2011). The main difference between the standard and coastal processing approaches is that the former uses a Hamming window, while the latter is a simple rectangular ("box") window. The validation report for the coastal product notes that the box-averaged product may potentially experience lower geophysical noise than the Hamming window product (Verhoef and Stoffelen 2011); this possibility will be discussed further in a later section. Due to the shorter ASCAT data record and swath coverage differences, there are fewer triplets for the ASCAT matchups: 836 triplets for the $12.5-\mathrm{km}$ product, 941 for the $25-\mathrm{km}$ product, and 138 for the coastal 
(a)
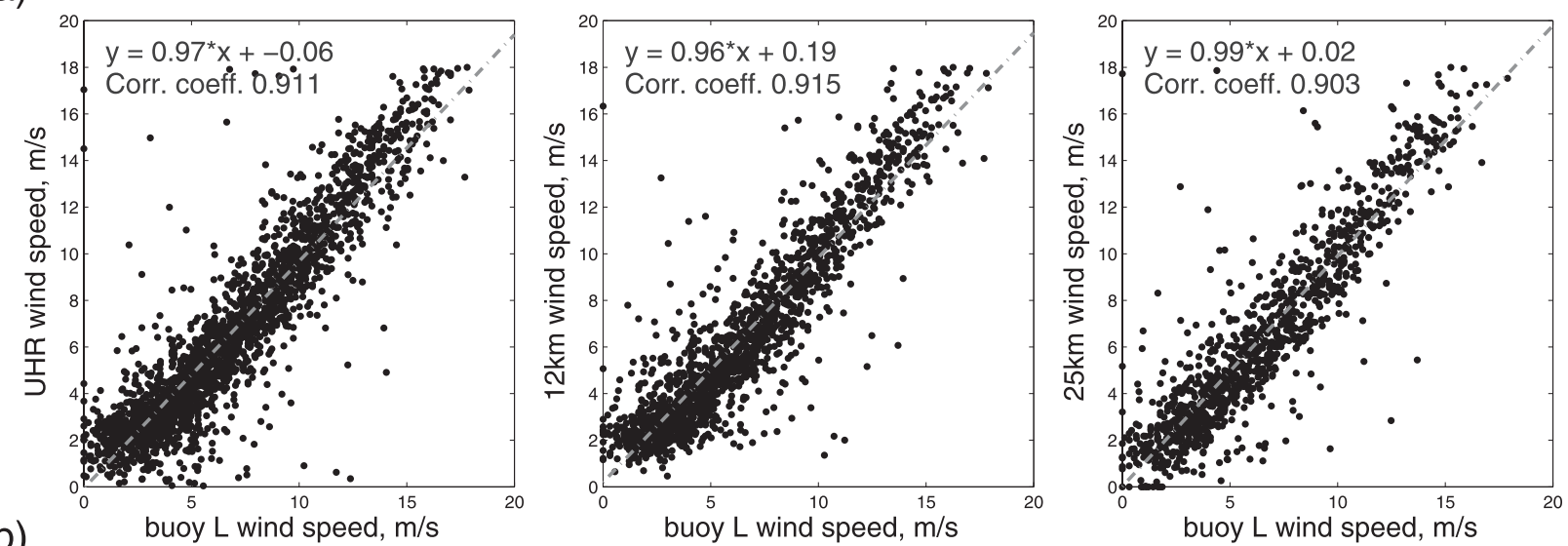

(b)
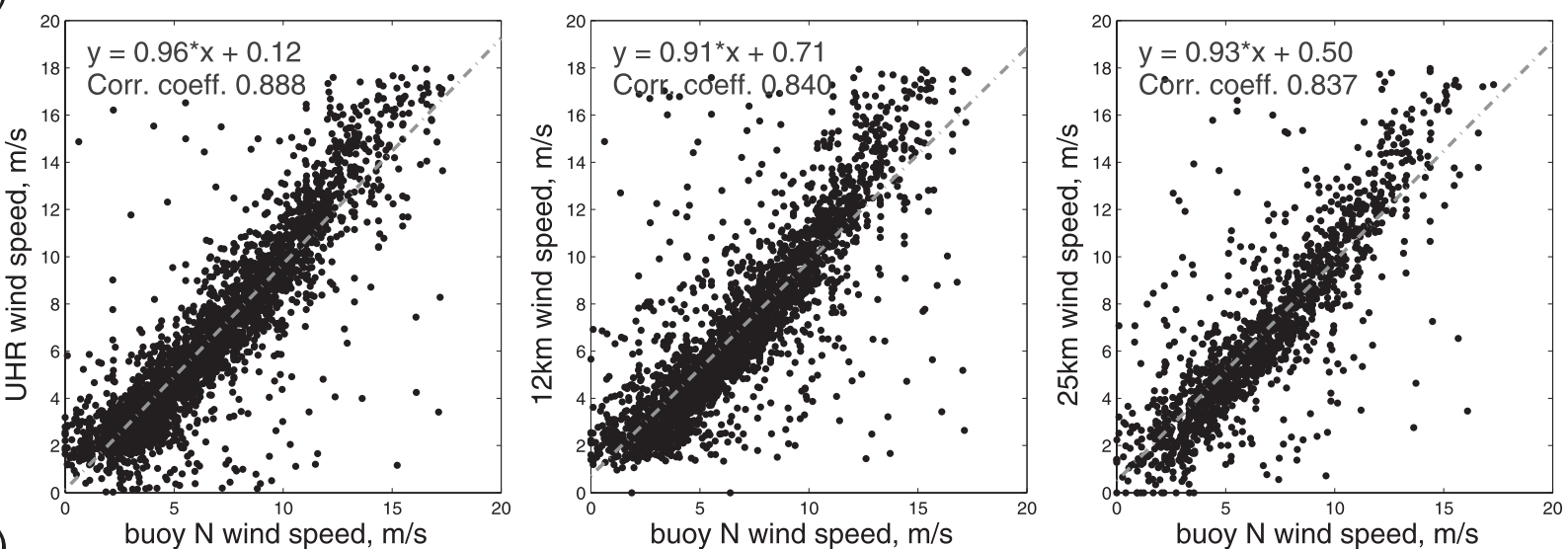

(c)
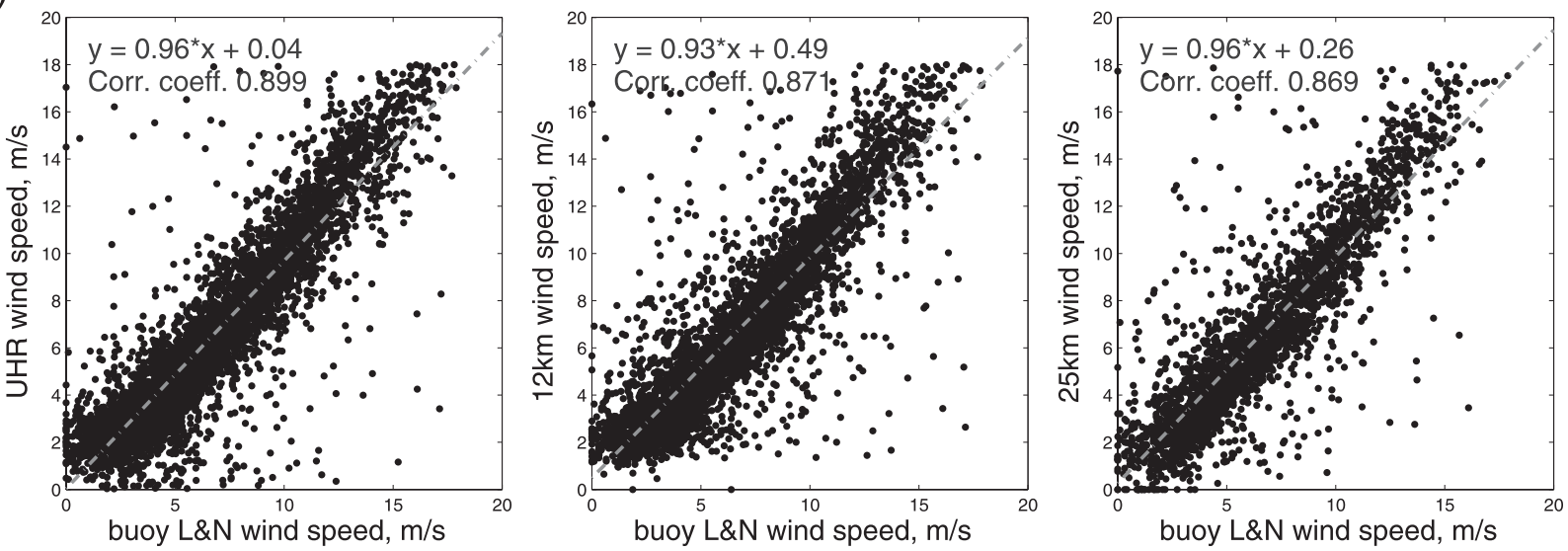

FIG. 4. Wind speed measurement comparisons between the earth-relative buoy and collocated QuikSCAT observations at (a) buoy L, (b) buoy N, and (c) data for both sites. Panels across each row represent the differing QuikSCAT wind products with highest-resolution UHR data on the left, the $12.5-\mathrm{km}$ product in the middle, and the $25 \mathrm{~km}$ on the right. A dashed line provides the result from a linear regression fit; this fit and the correlation coefficient are noted in the top left of each panel.

product after quality control. For satellite ocean altimetry, we collocate wind speed estimates obtained using three separate Ku-band altimeters: Jason-1, Jason-2, and Envisat, using project Geophysical Data Records as extracted from the Radar Altimetry Database System (Scharroo 2008). Note that the nominal spatial resolution for the altimeter is $6 \mathrm{~km}$, inherently a finer spatial scale and, thus, less error due to spatial smoothing should be obtained. Any measurements within a $15-\mathrm{km}$ radius of buoy $\mathrm{N}$ were averaged, yielding 388 total collocated triplets over the period 2004-present. It should also be noted that due to differing satellite tracks, neither 
ASCAT nor the altimeters were able to provide collocations with buoy L.

\section{Results}

Analyses in this study are focused on isolating the current impact on scatterometer $U_{10 \mathrm{~N}}$ explicit in Eq. (1). First, we assume that wind speed residuals between a microwave satellite wind and the fixed-earth reference mooring wind measurement relates to $\mathbf{U}_{s}$ in this equation. Given the model in Eq. (1), we assume that it is only the component of the current vector in the direction of the wind that will contribute to a difference between a scatterometer-retrieved (stress based) wind vector and a wind vector measured by an anemometer. Therefore, in this study we will examine the residual against an effective surface velocity $\left(u_{p}\right)$ where the relevant surface velocity is the vector component projected onto the buoy's wind direction ( $\left.\theta_{\text {bwind }}\right)$ and defined as

$$
u_{p}=\left|\mathbf{U}_{s}\right| * \cos \left(\theta_{s}-\theta_{\text {bwind }}\right) \text {, }
$$

where $\left|\mathbf{U}_{s}\right|$ is the surface current magnitude and $\theta_{s}$ is the direction of the current in meteorological convention.

This approach differs somewhat from past field studies that separately address mostly zonal wind and current components within sites having well-defined large-scale currents (Quilfen et al. 2001; Kelly et al. 2005) along these axes. By using $u_{p}$, all possible combinations of wind and current directions are enfolded in a single statistical assessment. The inclusion of all conditions should allow us to best capture large currents associated with local wind and circulation patterns beyond just the tidal flow (Smith et al. 2003), but may also lead to a higher level of non-current-induced variability in the wind residual due to the range of other processes and conditions that can affect wind residual assessment in the coastal zone (Freilich and Dunbar 1999; Plagge et al. 2009; Portabella and Stoffelen 2009), such as orographic effects on wind, multiscale weather patterns, changing fetch, strong air-sea temperature differences, and breaking waves.

Before proceeding, we also examined the implicit assumption that scatterometer wind direction estimates are invariant with respect to the buoy wind under the observed range of current vectors. This assumption is made in our progression from Eq. (1) to Eq. (2); if a surface current normal to the wind would cause a bias in the direction retrieved from the scatterometer, the use of Eq. (2) would be limited or confusing. However, investigation showed no significant bias in scatterometer direction related to currents. For our dataset, no angular difference (i.e., $\theta_{s}-\theta_{\text {bwind }}$ ) sector exhibited biases greater than $6^{\circ}$. Therefore, using speed or wind vector differences yields nearly equivalent results and the focus is solely on wind speed versus the wind-projected current going forward.

QuikSCAT wind residuals versus $u_{p}$ for all data contained in the prefiltered matchup datasets at both buoys ( $\mathrm{L}$ and $\mathrm{N}$ ) are presented in Fig. 5. A separate panel is shown for each of the three Ku-band scatterometer products. Positive (negative) $u_{p}$ indicates that the projected current and wind are aligned in the same (opposite) direction. The data scatter about zero with an RMS of nearly $2 \mathrm{~m} \mathrm{~s}^{-1}$. Most importantly, there is a clear, though small, negative correlation evident in the data, indicating that the scatterometer wind exceeds the buoy result in the event of an opposing current. Noted linear regression fit parameters are similar for all three resolutions and show slopes of -0.8 to -0.9 , highlighted by the gray dashed line in each panel in Fig. 5. The linear correlation coefficients $R$ are quite similar $(-0.185$, UHR; $-0.161,12.5 \mathrm{~km}$; and $-0.166,25 \mathrm{~km}$ ) and the $95 \%$ confidence interval for $R$ lies above -0.12 for all three cases.

Figure 6 also presents the same data after bin averaging versus $u_{p}$, with a change in the $y$ axis to accentuate the $1: 1$ anticorrelation with currents that is expected if the scatterometer residuals are indeed current relative. The black-dashed line in Fig. 6 shows this ideal slope of -1 . A weighted linear least squares model is applied to the binned data, using the inverse of each bin's standard error as the weights (Bevington and Robinson (1992)); the resultant linear fit is plotted as a gray dash-dot line and shown as an equation in Fig. 6. Only bins containing at least 10 points contribute to the fit, to satisfy the central limit theorem. A histogram of samples in each bin is shown as a gray solid line. Fit coefficients and their uncertainty are provided in each panel in Fig. 5. To within the confidence intervals given, these slope estimates agree with those from the unweighted slope values given in Fig. 5 for each QuikSCAT resolution. Again, each QuikSCAT product yields a similar result of a negative slope lying between -0.82 and -0.85 . Also note that the significance level of the wind residual relationship versus $u_{p}$ is evident from the error bars, extending out to a range of $u_{p}$ of -0.6 to $0.6 \mathrm{~m} \mathrm{~s}^{-1}$. While the figures show combined results for buoys $\mathrm{L}$ and $\mathrm{N}$, those for the individual buoys were similar. All weighted fit parameters are provided in Table 1.

While these initial results show a clear correlation between speed residuals and $u_{p}$ and a slope of nearly -1 , the correlation coefficient values fall well below the levels of $0.4-0.6$ cited in past field scatterometer studies (Kelly et al. 2001; Quilfen et al. 2001). This evaluation includes all data collected without consideration for 

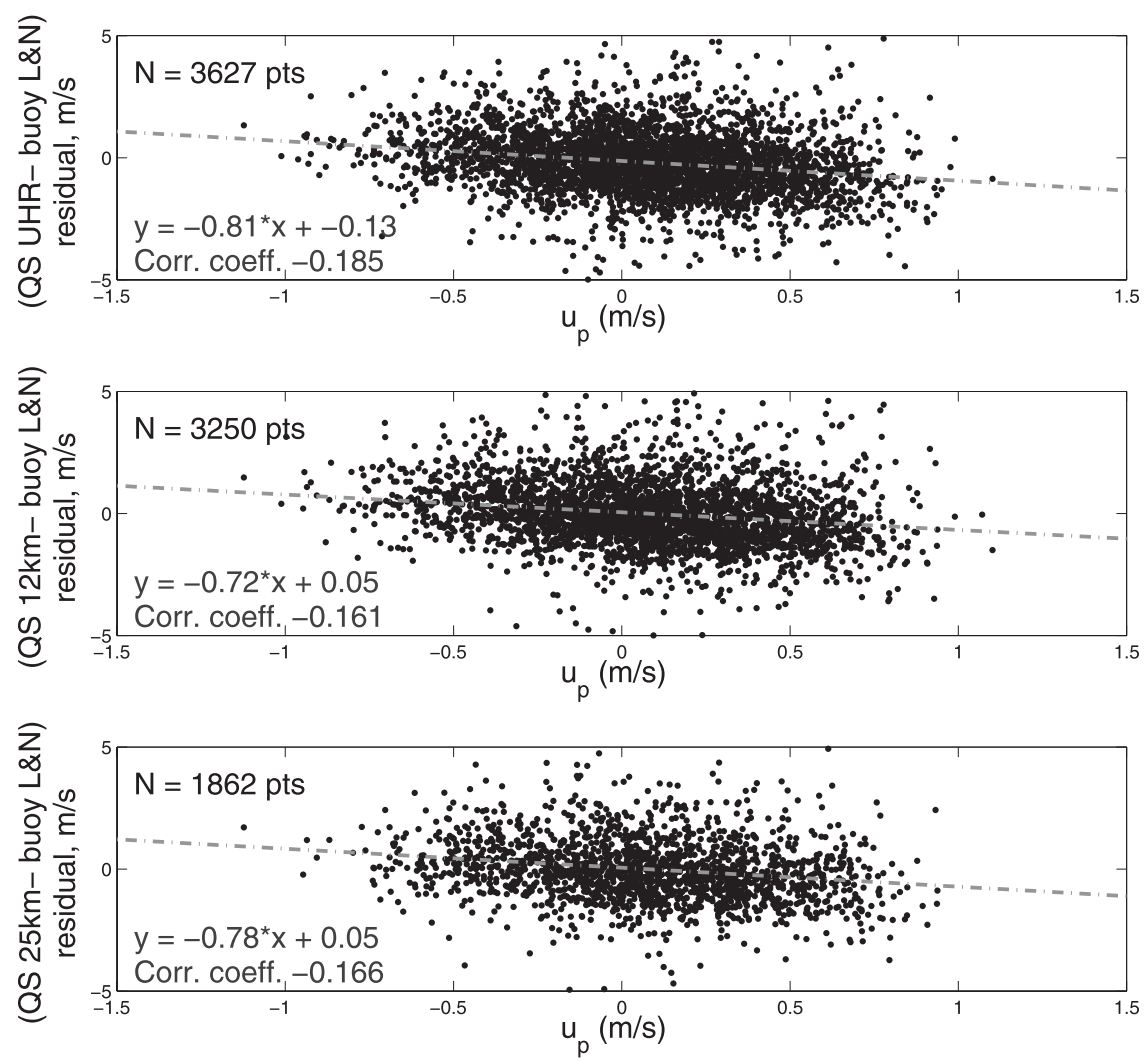

FIG. 5. Wind speed differences (QuikSCAT - buoy) vs the projected surface current velocity $u_{p}$ with results provided for each QuikSCAT wind product. Data represent all wind, wave, and current conditions within the datasets at buoys $\mathrm{L}$ and $\mathrm{N}$. The sample population $(N)$ is noted in each panel.

varied sea state and air-sea conditions. As noted in the introduction, detecting and reducing spurious correlations among factors (e.g., waves, atmospheric stability, currents, geophysical model function errors) controlling the scatterometer winds at the $1-2 \mathrm{~m} \mathrm{~s}^{-1}$ level is difficult. As one example, consider the possible case where stable atmospheric conditions systematically bias the scatterometer winds low and also regularly coincide with positive $u_{p}$ in our region. This would negate or ameliorate the current impact depending on the covariance between these effects. To investigate whether current impacts can be more clearly resolved, we computed the aforementioned statistics after filtering by differing wind, wave, and atmospheric stability regimes (cf. Ebuchi et al. 2002). Results, including linear correlation coefficients, are given in Table 2. The slopes and correlations are not significantly different across Table 2 for varied scatterometer resolutions.

In general, the best results are seen for moderate winds, low sea states $(<1.6 \mathrm{~m})$, and near-neutral stability. This region does not experience a wide range of wave conditions and thus wave impacts are unlikely to be a significant factor in the results of this study. But increased noise and/or bias in scatterometer-buoy wind comparisons at low winds, due in part to the variability of the wind field at these speeds (Plagge et al. 2009; Ebuchi et al. 2002; Kelly et al. 2005), and to strongly stable or unstable boundary layer conditions, are likely contributors to the weaker correlations and lower or higher slopes. The variation in regression slopes and correlation values is considered to be combined geophysical and statistical effects more than an actual increased or decreased dependence on surface current. From numerous past studies addressing conditions associated with the best agreement between scatterometer and buoy winds, it is reasonable to assume that the best geophysical conditions to focus on surface current impact assessments are those of near-neutral atmospheric stability $(-0.4 \leq z / L \geq 0.1)$ and moderate wind speeds of $5-10 \mathrm{~m} \mathrm{~s}^{-1}$. Under those filtering conditions, we achieve correlations of -0.250 (UHR), -0.256 (12.5 km), and $-0.266(25 \mathrm{~km})$ with the bin-averaged results shown in Fig. 7. By contrast, the conditions that yield the weakest correlation are those for light winds and unstable 

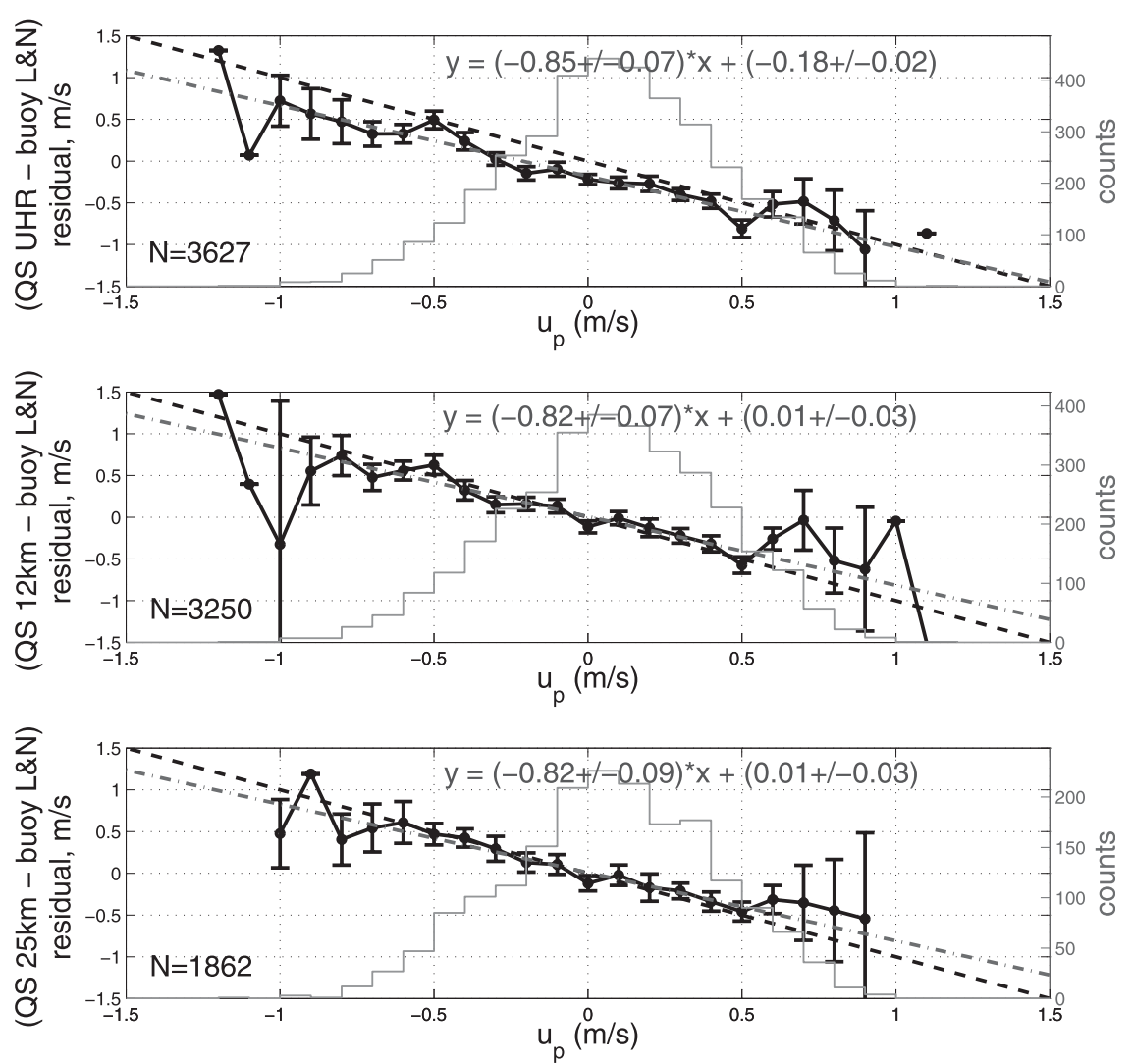

FIG. 6. Bin-averaged wind speed differences (QuikSCAT - buoy) vs $u_{p}\left(10 \mathrm{~cm} \mathrm{~s}^{-1}\right.$ bins) for the same datasets in Fig. 5. Error bars represent the standard error within each bin. The black dashed curve represents a $-1: 1$ line while the gray dotted-dashed is the result from a weighted linear regression (see text). The sample population is noted in each panel.

boundary layers $(z / L<-0.4)$. In this case, the relationship is far from $-1: 1$ for all resolutions (Fig. 8), and the correlations are quite low: -0.122 (UHR), -0.071 $(12.5 \mathrm{~km})$, and $-0.116(25 \mathrm{~km})$.

Results from a similar evaluation of C-band ASCAT satellite scatterometer data are shown in Figs. 9 and 10. The lower data sample size is apparent in comparison to QuikSCAT but the scatter of the data is somewhat reduced and, most importantly, a negative correlation versus $u_{p}$ is also observed. However, it is also clear that there is a large difference in the slopes observed for the $12-$ and $25-\mathrm{km}$ products ( -0.53 and -0.51 for binned slopes), and that for the coastal ASCAT product ( -1.07 binned slope). Only the coastal products lie near that observed for the Ku-band QuikSCAT. The correlation coefficient for the coastal

TABLE 1. Slopes, intercepts, and their uncertainties for the weighted least squares fit of wind speed residuals $\left(\mathrm{m} \mathrm{s}^{-1}\right) \mathrm{vs} u_{p}$ for different QuikSCAT resolutions and for different buoys.

\begin{tabular}{lcccrrr}
\hline \hline & Resolution & Slope & Slope SD & $Y$ intercept & $Y$ intercept SD & Corr \\
\hline Buoy L & UHR & -0.83 & 0.10 & -0.23 & 0.03 & -0.201 \\
& $12 \mathrm{~km}$ & -0.87 & 0.10 & -0.04 & 0.04 & -0.195 \\
Buoy N & $25 \mathrm{~km}$ & -0.86 & 0.13 & 0.00 & 0.05 & -0.195 \\
& UHR & -0.87 & 0.09 & -0.15 & 0.03 & -0.175 \\
Buoys L and N & $12 \mathrm{~km}$ & -0.84 & 0.09 & +0.03 & 0.03 & -0.143 \\
& $25 \mathrm{~km}$ & -0.81 & 0.13 & 0.00 & 0.05 & -0.146 \\
& UHR & -0.85 & 0.07 & -0.18 & 0.02 & -0.185 \\
& $12 \mathrm{~km}$ & -0.82 & 0.07 & +0.01 & 0.03 & -0.161 \\
& $25 \mathrm{~km}$ & -0.92 & 0.10 & +0.01 & 0.03 & -0.166 \\
\hline
\end{tabular}


TABLE 2. Statistics from the same weighted least squares fit of wind residuals vs currents as in Table 1 but after filtering for different airsea interface conditions. Significant wave height and the Monin-Obukov stability length-scale parameter $L$ come from buoy observations; stability of the boundary layer is based on definitions in Large and Pond (1982). Results are for combined buoy L and N datasets.

\begin{tabular}{|c|c|c|c|c|c|c|}
\hline Regime/rule & Res. & Slope & Slope SD & $Y$ intercept & $Y$ intercept SD & Corr \\
\hline \multirow[t]{3}{*}{ Buoy wind speed $\leq 5 \mathrm{~m} \mathrm{~s}^{-1}$} & UHR & -0.82 & 0.10 & -0.14 & 0.03 & -0.192 \\
\hline & $12.5 \mathrm{~km}$ & -0.86 & 0.11 & +0.06 & 0.04 & -0.167 \\
\hline & $25 \mathrm{~km}$ & -1.00 & 0.15 & -0.01 & 0.05 & -0.161 \\
\hline \multirow{3}{*}{$5 \mathrm{~m} \mathrm{~s}^{-1}<$ buoy wind speed $\leq 10 \mathrm{~m} \mathrm{~s}^{-1}$} & UHR & -0.95 & 0.09 & -0.41 & 0.03 & -0.206 \\
\hline & $12.5 \mathrm{~km}$ & -0.98 & 0.09 & -0.21 & 0.03 & -0.213 \\
\hline & $25 \mathrm{~km}$ & -1.01 & 0.13 & -0.21 & 0.04 & -0.204 \\
\hline \multirow[t]{3}{*}{ Buoy wind speed $>10 \mathrm{~m} \mathrm{~s}^{-1}$} & UHR & -1.05 & 0.18 & +0.28 & 0.05 & -0.193 \\
\hline & $12.5 \mathrm{~km}$ & -0.94 & 0.22 & +0.42 & 0.07 & -0.112 \\
\hline & $25 \mathrm{~km}$ & -1.07 & 0.25 & +0.51 & 0.09 & -0.173 \\
\hline \multirow[t]{3}{*}{ Significant wave height $\leq 1 \mathrm{~m}$} & UHR & -0.96 & 0.12 & -0.44 & 0.04 & -0.198 \\
\hline & $12.5 \mathrm{~km}$ & -0.94 & 0.11 & -0.27 & 0.04 & -0.238 \\
\hline & $25 \mathrm{~km}$ & -1.01 & 0.14 & -0.34 & 0.05 & -0.223 \\
\hline \multirow[t]{3}{*}{$1 \mathrm{~m}<$ significant wave height $\leq 1.6 \mathrm{~m}$} & UHR & -1.17 & 0.14 & -0.28 & 0.05 & -0.262 \\
\hline & $12.5 \mathrm{~km}$ & -1.24 & 0.12 & -0.11 & 0.05 & -0.295 \\
\hline & $25 \mathrm{~km}$ & -1.28 & 0.17 & -0.11 & 0.06 & -0.268 \\
\hline \multirow[t]{3}{*}{ Significant wave height $>1.6 \mathrm{~m}$} & UHR & -0.82 & 0.12 & +0.17 & 0.04 & -0.160 \\
\hline & $12.5 \mathrm{~km}$ & -0.86 & 0.12 & +0.35 & 0.04 & -0.166 \\
\hline & $25 \mathrm{~km}$ & -0.84 & 0.18 & +0.41 & 0.06 & -0.132 \\
\hline \multirow[t]{3}{*}{$-0.4 \leq z / L \leq 0.1$ (near neutral) } & UHR & -0.86 & 0.09 & -0.06 & 0.03 & -0.210 \\
\hline & $12.5 \mathrm{~km}$ & -0.90 & 0.10 & +0.11 & 0.04 & -0.18 \\
\hline & $25 \mathrm{~km}$ & -0.79 & 0.13 & +0.07 & 0.05 & -0.194 \\
\hline \multirow[t]{3}{*}{$z / L>0.1$ (stable $)$} & UHR & -1.00 & 0.10 & -0.61 & 0.04 & -0.196 \\
\hline & $12.5 \mathrm{~km}$ & -0.95 & 0.10 & -0.41 & 0.04 & -0.168 \\
\hline & $25 \mathrm{~km}$ & -0.94 & 0.15 & -0.35 & 0.05 & -0.149 \\
\hline \multirow[t]{3}{*}{$z / L<-0.4$ (unstable) } & UHR & -0.70 & 0.22 & +0.57 & 0.06 & -0.131 \\
\hline & $12.5 \mathrm{~km}$ & -0.72 & 0.23 & +0.67 & 0.07 & -0.098 \\
\hline & $25 \mathrm{~km}$ & -0.55 & 0.35 & +0.57 & 0.10 & -0.127 \\
\hline \multirow[t]{3}{*}{ Best: moderate wind, near neutral } & UHR & -0.93 & 0.11 & -0.25 & 0.04 & -0.250 \\
\hline & $12.5 \mathrm{~km}$ & -0.96 & 0.12 & 0.11 & 0.04 & -0.256 \\
\hline & $25 \mathrm{~km}$ & -1.00 & 0.17 & -0.16 & 0.06 & -0.266 \\
\hline \multirow[t]{3}{*}{ Worst: light wind, unstable } & UHR & -0.52 & 0.28 & +0.66 & 0.08 & -0.122 \\
\hline & $12.5 \mathrm{~km}$ & -0.55 & 0.29 & +0.78 & 0.09 & -0.071 \\
\hline & $25 \mathrm{~km}$ & -0.31 & 0.46 & +0.69 & 0.13 & -0.116 \\
\hline
\end{tabular}

product of -0.48 is also elevated beyond that seen for any other dataset.

Altimeter and buoy wind residuals versus $u_{p}$ are shown in Figs. 11 and 12, respectively. As previously mentioned, only observations at buoy $\mathrm{N}$ are used because the passage of altimeter tracks near to buoy L was much more limited. Recall that this dataset represents a compilation drawn from the combination of Ku-band sensors aboard the Jason-1 and -2, and Envisat platforms. While again the sample population is much lower than for QuikSCAT, these data show remarkably similar results to those shown for QuikSCAT (see Fig. 6). The weighted least squares fit in Fig. 12 yields a slope of $-0.97 \pm 0.26$ and the linear correlation coefficient of 0.204 is near that seen for the scatterometer. These altimeter results are for the full range of observed surface conditions without filtering for wind regimes or stability effects, due to the limited number of samples.

\section{Discussion}

The observational evidence to date concerning the treatment of scatterometer ocean wind as a currentrelative velocity lies primarily within five studiesQuilfen et al. (2001), Cornillon and Park (2001), Dickinson et al. (2001), Kelly et al. (2001), and Kelly et al. (2005) with the former addressing the C-band European Remote Sensing Satellite (ERS) scatterometer and the remainder Ku-band NSCAT or QuikSCAT data. In most cases, these studies relate separate long-term averages of currents and of wind (or wind vector) residuals leading to convincing causal evidence such as Fig. 4 in Cornillon and Park (2001), Fig. 6 in Chelton et al. (2004), and Fig. 3 in Kelly et al. (2001). However, only Dickinson et al. (2001) provide a quantitative estimate of the transfer function between observed zonal wind differences and the zonal current with their linear regression coefficient being 1.3 at $\mathrm{Ku}$ band, suggesting 

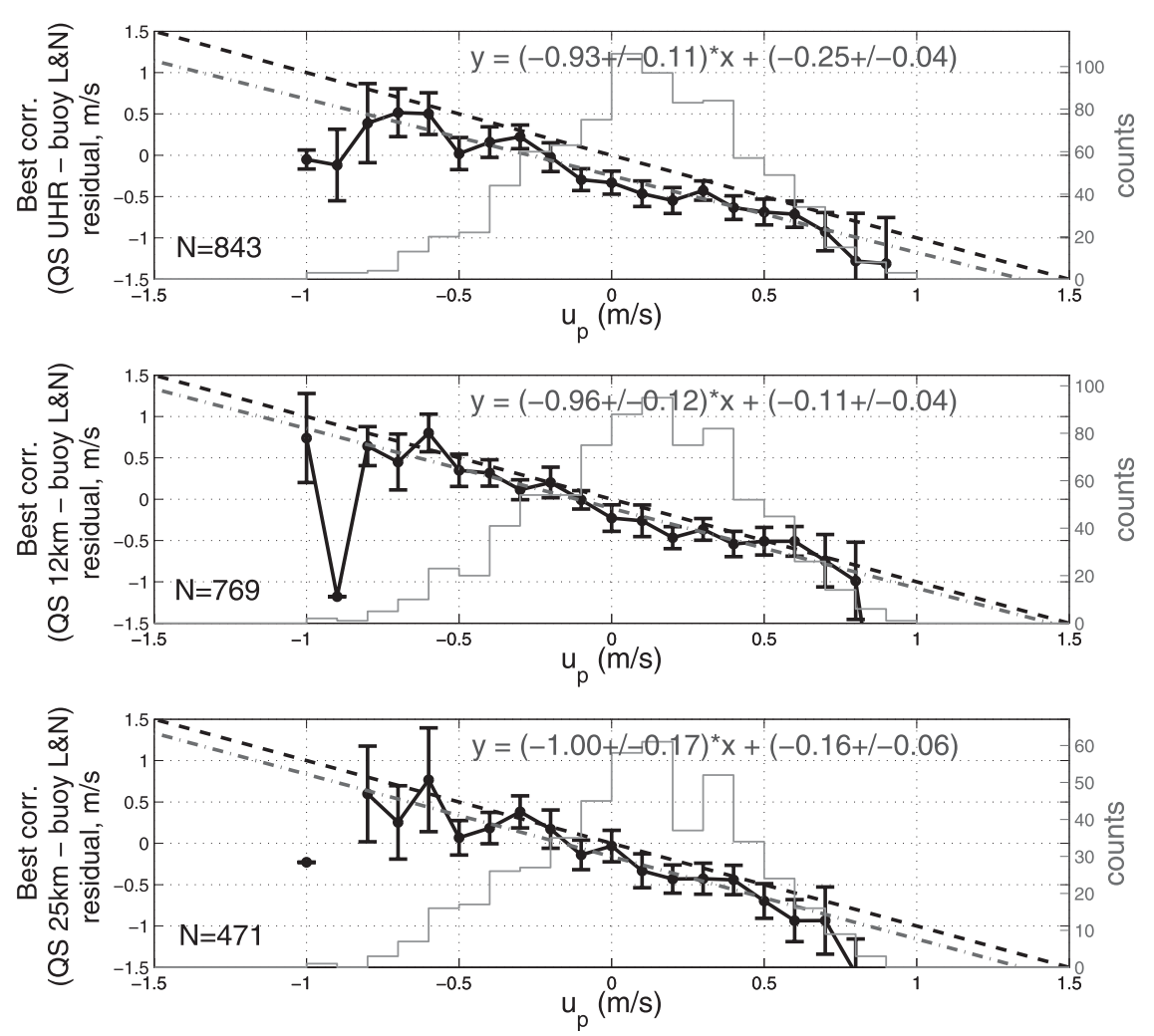

FIG. 7. Binned wind speed residuals (QuikSCAT - buoy) vs the effective surface current for the conditions chosen to show the best correlation: moderate wind speed and neutral atmospheric stability. This and all subsequent binned figures follow the methodology of Fig. 6.

enhanced wind perturbation beyond the 1:1 relationship with $\mathbf{U}_{s}$ in Eq. (1). Results from the C-band ERS scatterometer seen in Fig. 10 in Quilfen et al. (2001) indicate a slope possibly exceeding 1.0, but actual linear regression coefficients are not provided. Given the low value of the linear correlation coefficient and varied noise sources contributing to mask current impacts in all of these studies, it is understandable that direct and formal quantification has been difficult. Results presented here for QuikSCAT provide a new and complementary quantification with detailed estimates of uncertainty, as summarized in Fig. 7 and Table 2. The observed relationship between wind residuals and the effective current in the Gulf of Maine region clearly affirms that the scatterometer yields a current-relative wind. Moreover, the data lead us to conclude that for the $\mathrm{Ku}$-band scatterometer there is no statistical justification to deviate from a slope of 1.0 with the actual bestcase isolation for currents yielding a slope of $-0.96 \pm$ 0.12 (for $12-\mathrm{km}$ data). The large sample population and use of the daily variations in tidal flow contained in this study seem to allow isolation of the phenomenon, but we do note that much averaging is required as the circulation dynamics near our buoys L and N (Smith et al. 2003) are much more active than within the persistent warm-core rings of the large-scale currents used in previous investigations, possibly leading to increased differences due to time-and-space lags. This is the likely reason for the observed linear correlation coefficients being nearer to 0.2 as opposed to $0.4-0.6$ cited earlier. While it is possible that choosing a different scatterometer solution (ambiguity) rather than the standard "best case" outcome (see section 2) might lead to slightly higher correlations, these results are based on only the most likely choice as given by the DIRTH algorithm, as that is the most commonly used form of the scatterometer data product.

Another possible contribution to low correlations is boundary layer (BL) modification due to stability. For a two-layer BL model, the inner (surface) layer is logarithmic and corrected for stratification, humidity, and surface roughness [the neutral version of this is given as Eq. (1)], and the outer is a stratification-dependent Ekman layer, associated with rotation of the wind with height and stability (Businger and Shaw 1984; Brown and Liu 1982). At the surface, it is assumed that the 

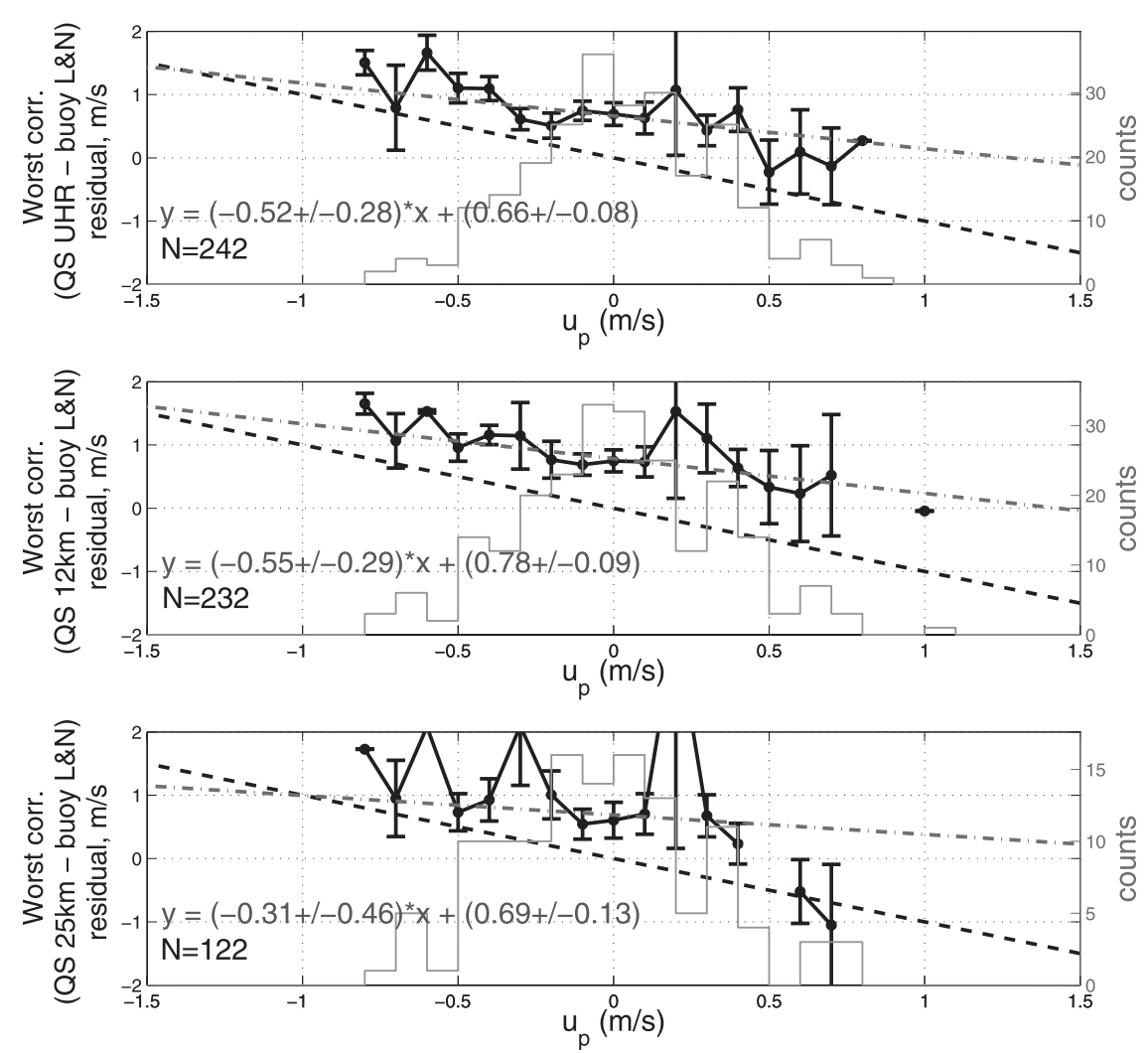

FIG. 8. Binned wind speed residuals (QuikSCAT - buoy) vs the effective surface current for conditions giving the worst correlation: light wind and unstable boundary layer.

stress direction is the same as the wind direction. But in certain circumstances, the direction of the wind at the height of the anemometer on the buoys $(3 \mathrm{~m})$ may have already been affected by stratification (Businger and Shaw 1984, their Fig. 2), causing it to be different from the direction derived at the surface from the scatterometer. This turning or rotation could impact the validity of $u_{p}$ as defined and add noise to the overall results. This would be especially true during stable conditions. However, given the methods for calibrating the scatterometer GMFs, using the basic surface layer model and the buoy wind direction without an additional turning angle is sufficient for a study containing the range of conditions presented here (R. Foster 2012, personal communication).

Results from section 3 also serve to address the question of equal treatment of C-band and Ku-band scatterometer data as well as that from systems such as the microwave altimeter. It is understood that the ocean radar backscatter for each sensor is uniquely related to the transmit frequency, polarization and incidence angle, and the interaction of the signal with the spectrum of waves at the sea surface. However, for these three systems and most passive and active microwave wind sensors, the fundamental issue of a changing bottom kinematic boundary condition should lead to a current-relative wind for the cases of large-scale currents. In this study we find this to be the case, where the C-band ASCAT coastal wind product data, the Ku-band altimeter winds, and QuikSCAT all yield statistically similar results over the same buoy sites. Knowing the altimeter reflects a broader integration of wave scales in its backscatter and wind estimates compared to the weighting of scatterometers toward 2-8-cm-scale gravity-capillary wave roughness scales (cf. Mouche et al. 2007), we infer that all wave scales shorter than roughly $10-20 \mathrm{~m}$ are, on average, adjusted to the local wind and surface current environment. This is also in agreement with recent wavecurrent interaction modeling efforts (Kudryavtsev et al. 2012). One can then expect similar results for lowerfrequency radar (e.g., L band) and for passive microwave systems such as Special Sensor Microwave Imager (SSM/I), Advanced Microwave Scanning Radiometer for Earth Observing System (AMSR-E), and WindSat. Our results also offer some insight into the spatial scale of currents near buoys N and L in the Gulf of Maine and, in turn, explain why the ASCAT data in the top panels of Figs. 9 and 10 differ from ASCAT coastal product 

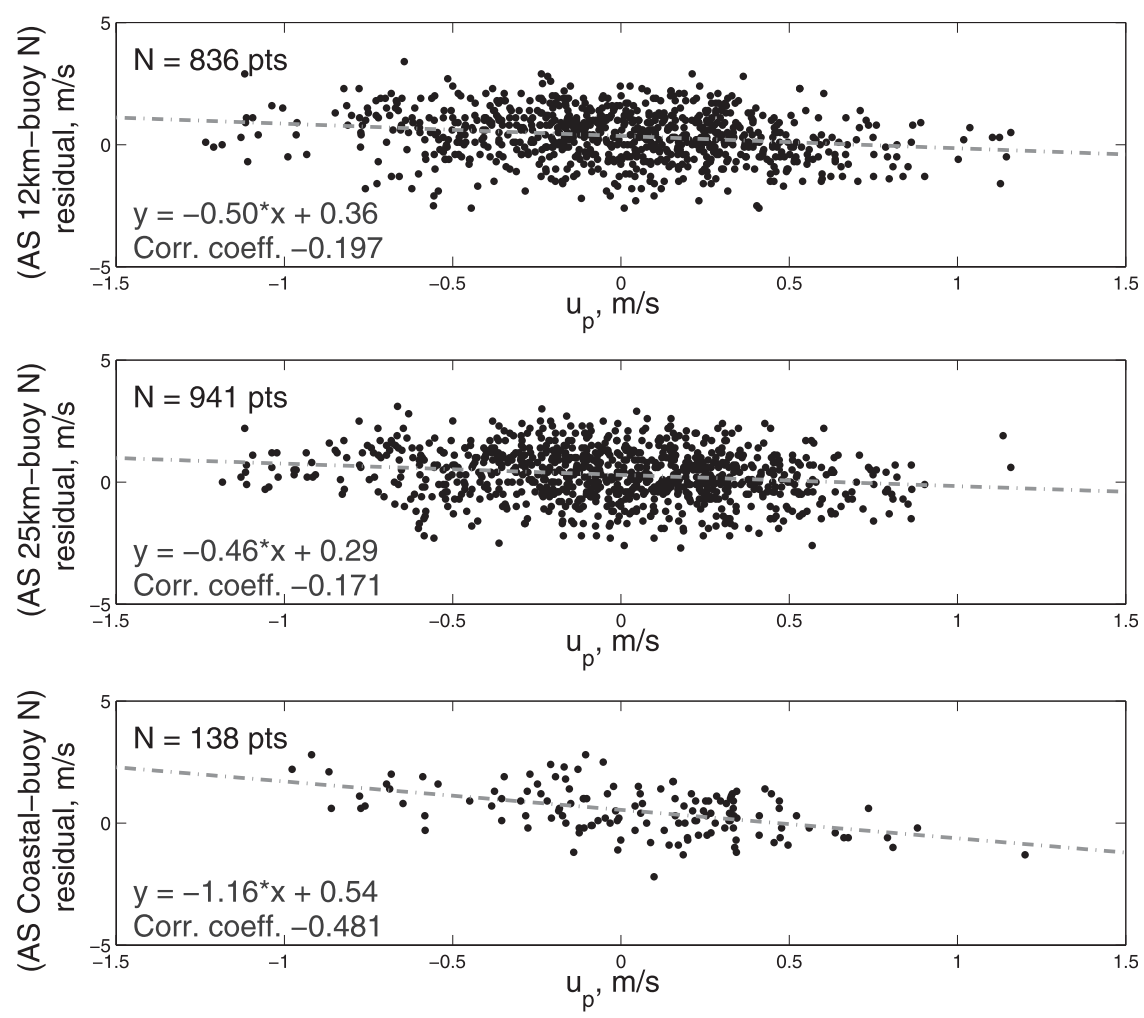

FIG. 9. Wind speed differences (ASCAT - buoy) vs the projected surface current velocity $u_{p}$ with results provided for each ASCAT wind product. Data represent all wind, wave, and current conditions within the dataset at buoy N, during 2007-11.

findings. Similar current-relative regression statistics are observed for all three QuikSCAT data products spanning down from 25 to $12 \mathrm{~km}$ to the nominally $5-\mathrm{km}$ UHR. This is not the case for the ASCAT data where the relationship between currents and the wind residuals is largely lost for the 25- and 12-km data. This apparent difference between ASCAT and QuikSCAT is known to be a consequence of the data processing window rather than physics. Once we incorporated the newer coastal product into the study, it became clear that the shallow slopes obtained using data produced with the standard spatial Hamming window (of order $50 \mathrm{~km}$ at the $3-\mathrm{dB}$ points) used to filter ASCAT 25- and 12-km data resulted in a satellite wind footprint smearing. This is consistent with the expectation that spatial averaging beyond $25 \mathrm{~km}$ would exceed the typical zonal length scale of currents in the Northeast Channel near buoy B as well as northward at buoy L (Chen et al. 2011). Future studies using ASCAT data in any buoy-satellite wind comparisons should closely consider these spatial windowing issues.

To further discuss the issues related to the spatial variability of current interactions in scatterometry, a case study was developed to explore the effect across the marginal shelf region containing the two buoys. For this purpose, hindcast model surface wind data were differenced with scatterometer swath data to examine possible differences in wind field spatial structures in comparison to expected ocean currents. The weather model data come from regional multiresolution (3, 9, and $27 \mathrm{~km}$ ) Weather Research and Forecasting (WRF) model output (Skamarock and Klemp 2008) produced routinely at the University of New Hampshire (UNH). Our chosen products were the 3-hourly 9-km domain $10-\mathrm{m}$ wind vectors $(u$ and $v$ ) and surface air temperature fields. The WRF model version was 2.1.2 and the Yonsei University scheme was used to parameterize the planetary boundary layer (Hong et al. 2006). No ocean currents were used in the bottom boundary conditions for the WRF model runs and only climatological SST data were used. For diagnosing wind residuals, hourly hindcast oceanic surface current vectors were used from the Gulf of Maine Finite Volume Community Ocean Model (FVCOM) circulation model developed by Dr. Chen and colleagues the University of Massachusetts. Because it uses an unstructured grid, FVCOM's fields have no fixed resolution, but this output had spacing below $5 \mathrm{~km}$ at all nodes in our region of interest. For these data 

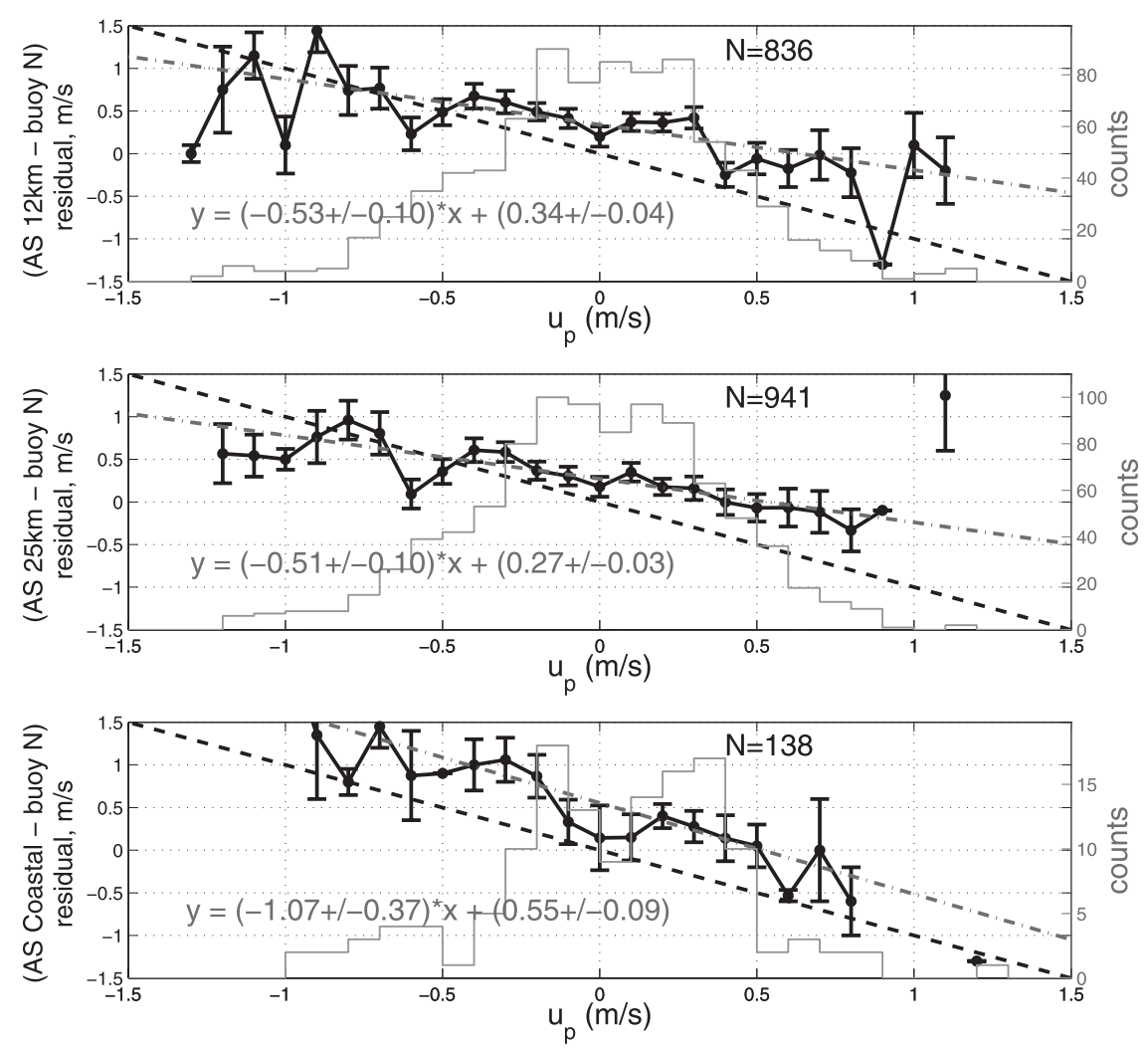

FIG. 10. Wind speed differences (ASCAT - buoy) binned according to $u_{p}$ (see Fig. 9 for correlations).

as well as the $12.5-\mathrm{km}$ QuikSCAT retrievals, linear interpolation was used to resample all data to $9 \mathrm{~km}$ for comparison with the atmospheric model.

Figure 13 presents one case of wind, current, and wind residual estimates from a $2^{\circ} \times 2^{\circ}$ area in the Gulf of Maine that includes buoys $\mathrm{L}$ and $\mathrm{N}$ and represents a region of strong $M_{2}$ tidal flow. Note that Fig. 1 provides a full regional map and the location of this region of interest. This specific case occurred near to 0000 UTC 27 December 2008 and is chosen to illustrate one extreme case of current impacts upon scatterometer winds. Here, the ocean model (2258 UTC 26 December 2008; see Fig. 13a) indicates flood tide conditions with the currents greater than $50 \mathrm{~cm} \mathrm{~s}^{-1}$ generally directed to the NNW and with enhanced flow near to Nova Scotia $\left(43.3^{\circ} \mathrm{N}\right)$ and also in the center near Browns Bank (closed

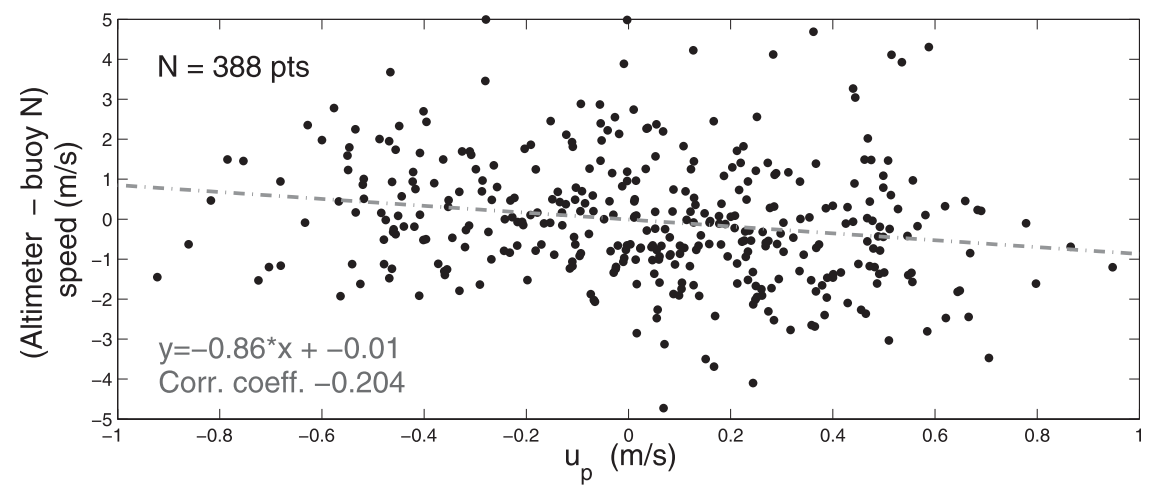

FIG. 11. Wind speed differences (altimeter - buoy) vs projected surface current velocity $u_{p}$. Data represent all wind, wave, and current conditions within the collocated dataset at buoy $\mathrm{N}$, during 2004-11. 


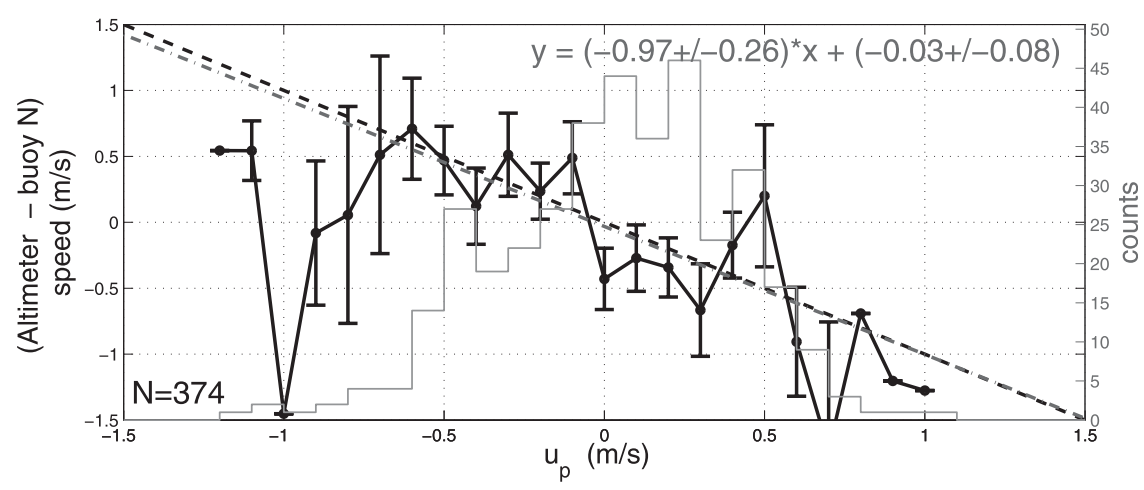

FIG. 12. Residuals for altimeter - buoy $\mathrm{N}$ wind speeds, binned according to $u_{p}$.

bathymetric contour near $\left.42.5^{\circ} \mathrm{N}, 66.2^{\circ} \mathrm{W}\right)$. QuikSCAT winds (2312 UTC 26 December 2008; Fig. 13c) are from the NNW, nearly in opposition to the tidal flow. This December case was also chosen for the uniformity in the sea surface temperature fields (not shown) to limit noncurrent impacts due to marine boundary layer and SST front features. The WRF-predicted winds (0000 UTC 27 December 2008) in Fig. 13b indicate a much smoother (a)

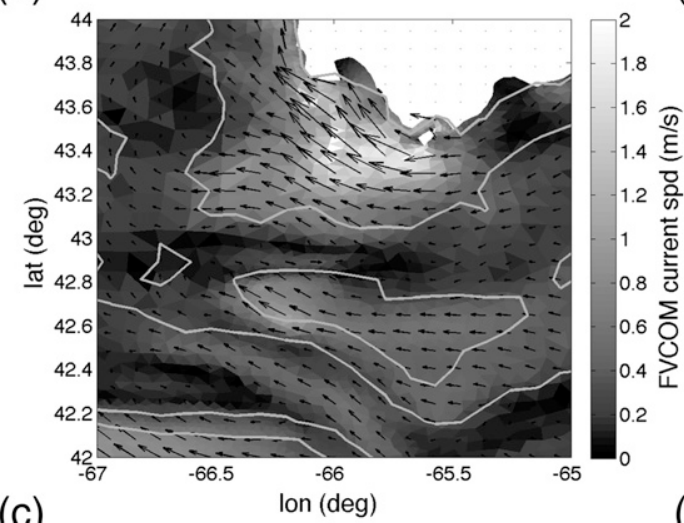

(c)

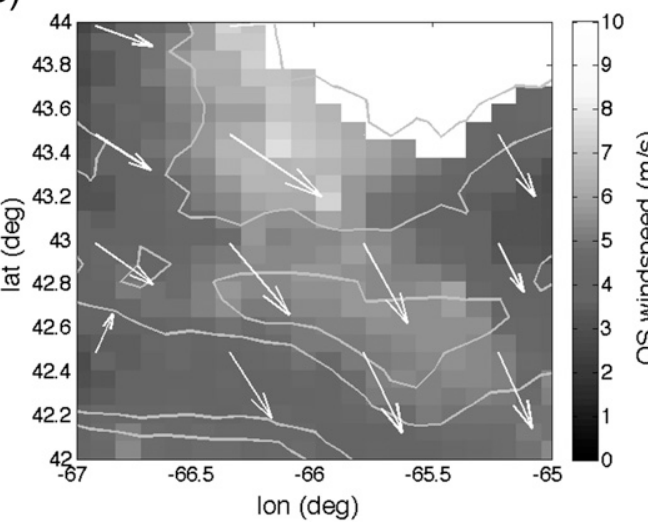

(b)

(d)
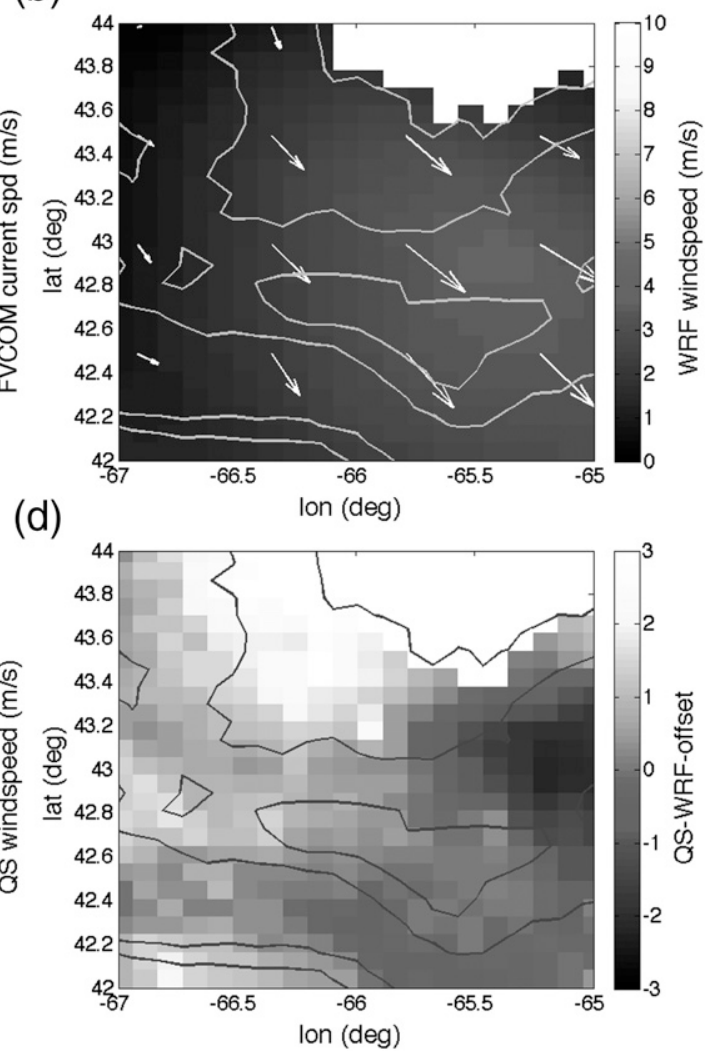

FIG. 13. Spatial view of the surface current effects on a QuikSCAT pass from 2301 UTC 26 Dec 2008, for the region southwest of Nova Scotia, depicted as a black box in Fig. 1. (a) FVCOM surface current magnitude (grayscale) and vectors (black arrows) from a run at 2258 UTC 26 Dec 2008. (b) WRF wind speed from a model run at 0000 UTC 27 Dec 2008 with white arrows showing subsampled WRF wind vectors. (c) The 12-km QuikSCAT wind speed; here, white arrows show subsampled QuikSCAT wind vectors. (d) Wind speed residual (scatterometer - model), including an offset determined by the mean wind speed difference and the mean current speed within the region of interest. 
spatial field than do those from QuikSCAT but they are from a similar direction (NNW). The average WRF wind speed within this region of interest (ROI) was $2.41 \mathrm{~m} \mathrm{~s}^{-1}$ below that from QuikScat, a number significantly in excess of the mean current $\left(0.4 \mathrm{~m} \mathrm{~s}^{-1}\right)$. We therefore create the wind residual between QuikSCAT and WRF to take into account the mean wind speed offset and the mean current offset, and arrive at the wind difference map in Fig. 13d. Note that the WRF data are for 0000 UTC and the scatterometer data are taken $1 \mathrm{~h}$ before, yet it is the spatial variation of the residuals (seen in Fig. 13d) that is most important here along with its relationship to the ocean currents given in Fig. 13a. The wind residual map indicates a clear enhancement of the scatterometer winds in Fig. 13d near to the coast of Nova Scotia and then periodic enhancement toward the SSW across to Georges Bank in the very SW corner of the image. These features are qualitatively similar to the dynamics of the FVCOM currents in Fig. 13a. While illustrative, we found it difficult to use this WRFFVCOM-QuikSCAT approach to rigorously examine current effects in this region. This is likely because of the combined issues of the time and space variability of the wind and currents, temporal differences between model and satellite products, and model inaccuracies. The studies performed using long-term averaging of scatterometer wind anomalies in large-scale and persistent currents (Chelton et al. 2004; Kelly et al. 2005; Park et al. 2006) have shown better results in that respect. However, as known from SAR studies, the instantaneous signatures of wave-current interactions are likely to exist at the surface in terms of roughness features, but may be difficult to isolate in scatterometer wind products due in part to the inherent $10-25-\mathrm{km}$ spatial resolution. Results from a recent SAR study in strong tidal currents (Hansen et al. 2012) may serve to illustrate this point. In their case, a scene with similar tidal magnitudes and scales is viewed in the coastal Norwegian Sea. As expected, SAR radar cross-section imagery (see Fig. 5 in Hansen et al. 2012) delineate current impacted regions at significantly finer scales than are found in our Fig. 13.

\section{Conclusions}

This study has used in situ mooring data and measurements of the tidally dominated currents in the Gulf of Maine to show that satellite winds derived from $\mathrm{Ku}$ band scatterometry, C-band scatterometry, and $\mathrm{Ku}$ band altimetry all provide a current-relative, rather than an earth-relative, wind speed. We are able to quantify this conclusion by finding slopes between buoy and satellite wind residuals and the wind-projected currents that lie at $-0.96 \pm 0.12,-1.07 \pm 0.37$, and $-0.97 \pm 0.26$ for the best-case 12-km QuikSCAT, coastal ASCAT, and a complement of altimeters, respectively. While the expectation and demonstration of ocean current effects upon scatterometer winds is not new, this study significantly advances the quantitative certainty in the currentrelative wind assumption made within Eq. (1), and in its application to winds derived both from satellite sensors that primarily respond to short-scale Bragg waves and those responding to a broader spectrum, such as the altimeter and radiometer.

On the whole, this study affirms that for surface currents with length scales of $10 \mathrm{~km}$ and longer, microwave remote sensing winds can be considered to be current relative; a result that is consistent with in situ and satellite scatterometer comparisons in large equatorial currents (Dickinson et al. 2001; Quilfen et al. 2001). The difference between earth-relative and current-relative winds can be quite pronounced across this coastal site where current magnitudes of $10 \%-20 \%$ of the wind velocity are quite common, and the impact on the pseudostress would be even higher. In fact, the region's reversing $M_{2}$ tide must be driving a measurable semidiurnal difference in the wind stress over a fairly large portion of the eastern Gulf of Maine for those cases when the synoptic winds near alignment with the tidal ellipse. Typical twice-daily sampling by scatterometry is unlikely to fully capture this feature, but predictive regional atmosphere-ocean modelers should consider this impact (cf. Kara et al. 2007). As discussed elsewhere (Chelton et al. 2004; Park et al. 2006), the present results also predict that wind stress curl fields computed from scatterometer data in this region will, at times, show a spatial structure that is closely related to the tidal flow and its interactions with bathymetry in the Gulf of Maine. Based on the similar findings of current impacts for the altimeter and scatterometer, it is expected that when the spatial scale of the currents and thus the kinematic boundary condition is large enough, even the $50-\mathrm{km}$ footprint of scanning microwave radiometers will provide current-relative winds; this has significant implications for developing accurate long-term climate records that merge satellite wind speed and wind vector data.

Acknowledgments. This study was made possible by the long-term field measurements openly provided by the University of Maine buoy group, and thanks go to Dr. Neal Pettigrew and his team, as well as NOAA Integrated Ocean Observing System funding. The authors also acknowledge the invaluable support and assistance of Dr. David Long at BYU; Dr. Rich Signell at USGS; Dr. Ernesto Rodriguez at JPL; Dr. Anton Verhoef with 
KNMI; Dr. C. Chen at the University of Massachusetts, Dartmouth; and Dr. Hui Feng at UNH, as well as three anonymous reviewers. Funding for the authors comes from NASA Graduate Student Research Program Grant NNX09AU69G and NASA Ocean Vector Wind Science Team Grant NNX10A085G.

\section{REFERENCES}

Bentamy, A., D. Croize-Fillon, and C. Periguad, 2008: Characterization of ASCAT measurements based on buoy and QuikSCAT wind vector observations. Ocean Sci., 4, 265274.

Bevington, P. R., and D. K. Robinson, 1992: Data Reduction and Error Analysis for the Physical Sciences. 2d ed. McGraw-Hill, $328 \mathrm{pp}$.

Bigelow, H. B., 1927: Physical Oceanography of the Gulf of Maine. U.S. Govt. Printing Office, 526 pp.

Bourassa, M. A., 2006: Satellite-based observations of surface turbulent stress during severe weather. Atmosphere-Ocean Interactions, W. Perrie, Ed., Advanced Fluid Mechanics Series, Vol. 39, Vol. 2, Wessex Institute of Technology, 3552.

Brown, R. A., and W. T. Liu, 1982: An operational-large scale marine planetary boundary layer model. J. Appl. Meteor., 21, 261-269.

Businger, J. A., and W. J. Shaw, 1984: The response of the marine boundary layer to mesoscale variations in sea-surface temperature. Dyn. Atmos. Oceans, 8, 267-281.

Chelton, D. B., M. G. Schlax, M. H. Freilich, and R. F. Milliff, 2004: Satellite measurements reveal persistent small-scale features in ocean winds. Science, 303, 978-983.

—, M. H. Freilich, J. M. Sienkiewicz, and J. M. Von Ahn, 2006: On the use of QuikSCAT scatterometer measurements of surface winds for marine weather prediction. Mon. Wea. Rev., 134, 2055-2071.

Chen, C., and Coauthors, 2011: Tidal dynamics in the Gulf of Maine and New England Shelf: An application of FVCOM. J. Geophys. Res., 116, C12010, doi:10.1029/2011JC007054.

Cornillon, P., and K.-A. Park, 2001: Warm core ring velocities inferred from NSCAT. Geophys. Res. Lett., 28, 575-578.

Dickinson, S., K. A. Kelly, M. Caruso, and M. J. McPhaden, 2001: Comparisons between the TAO buoy and NASA scatterometer wind vectors. J. Atmos. Oceanic Technol., 18, 799-806.

Donelan, M. A., and W. J. Pierson, 1987: Radar scattering and equilibrium ranges in wind-generated waves with application to scatterometry. J. Geophys. Res., 92 (C5), 4971-5029.

Dunbar, R., and Coauthors, 2006: QuikSCAT science data product user manual, version 3.0. JPL Doc. D-18053-Rev. A, Jet Propulsion Laboratory, Pasadena, CA, 85 pp.

Dupont, F., C. G. Hannah, and D. Greenberg, 2003: Modelling the sea level in the upper Bay of Fundy. Atmos.-Ocean, 43, 33-47.

Ebuchi, N., H. C. Graber, and M. J. Caruso, 2002: Evaluation of wind vectors observed by QuikSCAT/SeaWinds using ocean buoy data. J. Atmos. Oceanic Technol., 19, 2049-2062.

EUMETSAT, cited 2011: ASCAT products guide. Doc. No. EUM/ OPS-EPS/MAN/04/0028, v4C. [Available online at http:// www.eumetsat.int.]

Fairall, C. W., E. F. Bradley, J. E. Hare, A. A. Grachev, and J. B. Edson, 2003: Bulk parameterization of air-sea fluxes: Updates and verification for the COARE algorithm. J. Climate, 16, 571-591.

Freilich, M. H., and R. S. Dunbar, 1999: The accuracy of the NSCAT 1 vector winds: Comparisons with National Data Buoy Center buoys. J. Geophys. Res., 104 (C5), 11 231-11 246.

Hansen, M. W., V. Kudryavtsev, B. Chapron, J. A. Johannessen, F. Collard, K.-F. Dagestad, and A. A. Mouche, 2012: Simulation of radar backscatter and Doppler shifts of wave-current interaction in the presence of strong tidal current. Remote Sens. Environ., 120, 113-122.

Hersbach, H., 2010: Comparison of C-band scatterometer CMOD5.n equivalent neutral winds with ECMWF. J. Atmos. Oceanic Technol., 27, 721-736.

$\longrightarrow$ A. Stoffelen, and S. de Haan, 2007: An improved C-band scatterometer ocean geophysical model function: CMOD5. J. Geophys. Res., 112, C03006, doi:10.1029/2006JC003743.

Hong, S.-Y., Y. Noh, and J. Dudhia, 2006: A new vertical diffusion package with an explicit treatment of entrainment processes. Mon. Wea. Rev., 134, 2318-2341.

Johannessen, J. A., V. Kudryavtsev, D. Akimov, T. Eldevik, N. Winther, and B. Chapron, 2005: On radar imaging of current features: 2. Mesoscale eddy and current front detection. J. Geophys. Res., 110, C07017, doi:10.1029/2004JC002802.

Kara, A. B., E. J. Metzger, and M. A. Bourassa, 2007: Ocean current and wave effects on wind stress drag coefficient over the global ocean. Geophys. Res. Lett., 34, L01604, doi:10.1029/ 2006 GL027849.

Kelly, K. A., S. Dickinson, M. J. McPhaden, and G. C. Johnson, 2001: Ocean currents evident in satellite wind data. Geophys. Res. Lett., 28, 2469-2472.

,-- , and G. C. Johnson, 2005: Comparisons of scatterometer and TAO winds reveal time-varying surface currents for the tropical Pacific Ocean. J. Atmos. Oceanic Technol., 22, $735-745$.

Kudryavtsev, V., D. Akimov, J. Johannessen, and B. Chapron, 2005: On radar imaging of current features: 1 . Model and comparison with observations. J. Geophys. Res., 110, C07016, doi:10.1029/2004JC002505.

— A. Myasoedov, B. Chapron, J. A. Johannessen, and F. Collard, 2012: Imaging mesoscale upper ocean dynamics using synthetic aperture radar and optical data. J. Geophys. Res., 117, C04029, doi:10.1029/2011JC007492.

Large, W. G., and S. Pond, 1982: Sensible and latent-heat flux measurements over the ocean. J. Phys. Oceanogr., 12, 464-482.

Liu, W. T., and W. Tang, 1996: Equivalent neutral wind. JPL Tech. Rep. 96-17, Jet Propulsion Laboratory, 20 pp.

Lyzenga, D. R., 1998: Effects of intermediate-scale waves on radar signatures of ocean fronts and internal waves. J. Geophys. Res., 103 (C9), 18 759-18 768.

Manning, J. P., D. J. McGillicuddy Jr., N. R. Pettigrew, J. H Churchill, and L. S. Incze, 2009: Drifter observations of the Gulf of Maine Coastal Current. Cont. Shelf Res., 29, $835-845$.

Marmorino, G. O., B. Holt, M. J. Molemaker, P. M. DiGiacomo, and M. A. Sletten, 2011: Airborne synthetic aperture radar observations of spiral eddy slick patterns in the Southern California Bight. J. Geophys. Res., 115, C05010, doi:10.1029/ 2009JC005863.

Moore, R. K., and A. K. Fung, 1979: Radar determination of winds at sea. Proc. IEEE, 67, 1504-1521.

Mouche, A. A., B. Chapron, and N. Reul, 2007: A simplified asymptotic theory for ocean surface electromagnetic wave scattering. Wave Random Complex, 17, 321-341. 
O'Neill, L. W., D. B. Chelton, and S. K. Esbensen, 2005: Highresolution satellite measurements of the atmospheric boundary layer response to SST variations along the Agulhas Return Current. J. Climate, 18, 2706-2723.

Owen, M. P., K. M. Stuart, and D. G. Long, 2003: Ultra-highresolution near-coastal wind retrieval for QuikSCAT. Coastal Ocean Remote Sensing, R. J. Frouin, Ed., International Society for Optical Engineering (SPIE Proceedings, Vol. 6680), doi:10.1117/12.732681.

Park, K. A., P. Cornillon, and D. L. Codiga, 2006: Modification of surface winds near ocean fronts: Effects of Gulf Stream rings on scatterometer (QuikSCAT, NSCAT) wind observations. J. Geophys. Res., 111, C03021, doi:10.1029/ 2005JC003016.

Phillips, O. M., 1977: Dynamics of the Upper Ocean. 2d ed. Cambridge University Press, $336 \mathrm{pp}$.

Plagge, A. M., D. C. Vandemark, and D. G. Long, 2009: Coastal validation of ultra-high resolution wind vector retrieval from QuikSCAT in the Gulf of Maine. IEEE Geosci. Remote Sens. Lett., 6, 413-417.

Plant, W. J., 1977: Studies of backscattered sea return with a CW dual-frequency, X-band radar. IEEE J. Oceanic Eng., 2, 28-36.

Portabella, M., and A. Stoffelen, 2009: On scatterometer ocean stress. J. Atmos. Oceanic Technol., 26, 368-382.

Quilfen, Y., B. Chapron, and D. Vandemark, 2001: The ERS scatterometer wind measurement accuracy: Evidence of seasonal and regional biases. J. Atmos. Oceanic Technol., 18, 1684-1697.
Scharroo, R., 2008: RADS version 3.1 user manual and format specification. Delft University of Technology, $51 \mathrm{pp}$.

Skamarock, W. C., and J. B. Klemp, 2008: A time-split nonhydrostatic atmospheric model for weather research and forecasting applications. J. Comput. Phys., 227, 3465-3485.

Smith, P. C., R. W. Houghton, R. G. Fairbanks, and D. G. Mountain, 2001: Interannual variability of boundary fluxes and water mass properties in the Gulf of Maine and on Georges Bank: 1993-1997. Deep-Sea Res. II, 48, 37-70.

_, C. N. Flagg, R. Limeburner, C. Fuentes-Yaco, C. Hannah, R. C. Beardsley, and J. D. Irish, 2003: Scotian Shelf crossovers during winter/spring 1999. J. Geophys. Res., 108, 8013, doi:10.1029/2001JC001288.

Stoffelen, A., and D. Anderson, 1997: Scatterometer data interpretation: Estimation and validation of the transfer function CMOD4. J. Geophys. Res., 102 (C3), 5767-5780.

Tang, W. Q., W. T. Liu, and B. W. Stiles, 2004: Evaluations of highresolution ocean surface vector winds measured by QuikSCAT scatterometer in coastal regions. IEEE Trans. Geosci. Remote Sens., 42, 1762-1769.

Vandemark, D., J. B. Edson, and B. Chapron, 1997: Altimeter estimation of sea surface wind stress for light to moderate winds. J. Atmos. Oceanic Technol., 14, 716-722.

Verhoef, A., and A. Stoffelen, 2011: ASCAT coastal winds validation report. KNMI/Ocean and Sea Ice SAF Tech. Note SAF/OSI/CDOP/KNMI/TEC/RP/176, $19 \mathrm{pp}$.

Weissman, D., and H. Graber, 1999: Satellite scatterometer studies of ocean surface stress and drag coefficients using a direct model. J. Geophys. Res., 104 (C5), 11 329-11 335. 